\title{
Multimodal use of the porphyrin TMPyP: from cancer therapy to antimicrobial applications
}

\author{
Andres Garcia-Sampedroa, Andrea Tabero ${ }^{b}$, Ismahan Mahameda, Pilar Acedoa, ${ }^{*}$ \\ ${ }^{a}$ Institute for Liver and Digestive Health, University College London, Pond Street, NW3 2PG, London, UK \\ ${ }^{b}$ Departament of Biology, Universidad Autónoma de Madrid, Darwin 2, 28049, Madrid, Spain
}

Received date (to be automatically inserted after your manuscript is submitted)

Accepted date (to be automatically inserted after your manuscript is accepted)

\begin{abstract}
The cationic porphyrin meso-tetra(4-N-methylpyridyl)porphine (TMPyP) has a high yield of singlet oxygen generation upon light activation and a strong affinity for DNA. These advantageous properties have turned it into a promising photosensitiser for use in photodynamic therapy (PDT). In this review, we have summarised the current state-of-the-art applications of TMPyP for the treatment of cancer as well as its implementation in antimicrobial PDT. The most relevant studies reporting its pharmacokinetics, subcellular localisation, mechanism of action, tissue biodistribution and dosimetry have been discussed. Combination strategies using TMPyP-PDT together with other photosensitisers and chemotherapeutic agents to achieve synergistic anti-tumour effects and reduce resistance to therapy have also been explored. Finally, we have also addressed emerging applications of this porphyrin including nanoparticle-mediated delivery, controlled drug release, biosensing and G-quadruplex stabilisation for tumour growth inhibition. Altogether, this work highlights the great potential and versatility that TMPyP can offer in different fields of biomedicine such us cancer treatment or antimicrobial therapy.
\end{abstract}

KEYWORDS: porphyrins, photodynamic therapy, antimicrobial inactivation, reactive oxygen species, combination therapy, nanoparticles

*Correspondence to: Pilar Acedo, email: p.nunez@ucl.ac.uk 


\section{INTRODUCTION}

Porphyrins are aromatic macrocycles derived from porphine. These tetrapyrollic organic pigments play a key role in diverse biological processes. For example, a well-known family of iron-porphyrin complexes is heme, an essential prosthetic group of hemoproteins involved in oxygen transport and storage, among other functions. Porphyrins are also present in chlorophylls (magnesium porphyrins), which are vital components for photosynthesis [1].

The vast majority of clinically approved photosensitisers (PSs) used for biomedical applications are porphyrins and their derivatives [1]. Photodynamic Therapy (PDT) is a therapeutic modality that uses the potential of light-activatable compounds, such as porphyrins, to produce reactive oxygen species (ROS), mainly singlet oxygen $\left({ }^{1} \mathrm{O}_{2}\right)$, resulting in induction of cell death $[2,3]$. Moreover, porphyrins are capable to emit red fluorescence, a property used in fluorescence image-guided surgery to aid surgical interventions by accurately defining tumour margins [4]. The choice of light source and its wavelength is an important consideration depending on both the PS used as well as the depth of penetration required.

An optimal PS may fulfil several physical, chemical and photobiological properties to ensure its translatability: i) it should be a chemically pure drug with good stability and solubility in physiological fluids; ii) it should have a strong absorption in the spectral region $600-850 \mathrm{~nm}$; iii) it should have a high quantum yield of ROS production; iv) it should induce negligible dark toxicity and have specific uptake by the target tissue, and v) it should have relatively rapid clearance from the body to minimise phototoxic side effects $[2,5]$.

The first PS used in modern PDT was hematoporphyrin (Hp), a mixture of porphyrinic compounds characterised by Meyer-Betz at the beginning of the $20^{\text {th }}$ century. The chemical modification of $\mathrm{Hp}$ led to the synthesis of a hematoporphyrin derivative (HpD). Later, these discoveries supported the development of Photofrin ${ }^{\circledR}$, the first clinically approved PS to treat human cancers. Photofrin ${ }^{\circledR}$, a purified mixture of $\mathrm{HpD}$ oligomers, is still widely used but it also presents several drawbacks, including prolonged skin photosensitisation (4-6 weeks) and poor chemical purity. Consequently, extensive research in the field of PS design has led to the synthesis and development of second- and thirdgeneration PSs, including porphyrins and porphyrin derivatives, with optimised pharmacological properties making them more suitable for clinical applications [2,5]. Nowadays, some of the most promising clinically approved PSs are porphyrin-based compounds such as verteporfin $\left(\right.$ Visudyne $^{\circledR}$ ), a benzoporphyrin derivative widely used for the treatment of macular degeneration or 5-aminolevulinic acid (ALA) which after administration leads to the formation of protoporphyrin IX through the haem biosynthetic pathway, used to treat different types of skin disorders and cancer.

Porphine represents the core macrocycle of natural and synthetic porphyrins. However, its high insolubility has promoted the development of meso-tetra substituted porphyrins, with improved solubility [1]. One example is the cationic porphyrin meso-tetra (4-N-methylpyridyl) porphine (TMPyP). TMPyP is a heterocyclic compound containing four pyrrole rings linked by four methine bridges, which are essential for photochemical reactions and electron transport (Fig. 1A). TMPyP presents several absorption peaks in aqueous solution. The stronger absorption peak in the blue wavelength region of the visible spectrum is called the Soret band or B band $(\lambda \max =424 \mathrm{~nm})$ (Fig. 1B). Moreover, at longer wavelengths, its spectra contains a set of four weaker but still intense bands, called Q bands, which represent minor absorption peaks in the green and red wavelength zones of the visible spectrum (specifically at 518, 554, 585 and $630 \mathrm{~nm}$ ).

The use of red light to activate TMPyP is preferable when treating lesions located deeper into the tissues while the application of blue light is indicated for superficial lesions or antimicrobial applications. In any case, the selected light 
source should provide excitation wavelengths corresponding to the maximal absorbance peaks of the PS to ensure an optimal generation of ROS. In addition, TMPyP is characterised by a high quantum yield of singlet oxygen production in phosphate-buffered solution $(\Delta \Phi=0.7)$. The fluorescence emission of TMPyP can also be easily detected when it is excited by light in the Soret band wavelength region (around 400nm). TMPyP fluorescence emission in aqueous solution has two distinct peaks in the red region of the spectra, between 649-655 nm and 715-720 nm, respectively (Fig. 1B).

It is well established that PSs can localise in various organelles such as mitochondria, lysosomes, endoplasmic reticulum, Golgi apparatus or plasma membranes, and their subcellular localisation determine much of the signalling pathways activated after PDT protocols [3,6,7]. Studies carried out over the last decades have confirmed that PDT can evoke apoptosis, autophagy, mitotic catastrophe and necrotic cell death pathways, depending on a variety of parameters including the nature and intracellular localisation of the PS, cell genotype and PDT dose (PS concentration, light dose or both) $[8,9]$. For that reason, different groups have analysed the subcellular localisation of TMPyP based on its red fluorescence emission properties. TMPyP mainly accumulates into lysosomes when used at low concentrations (Fig. 1C) but after light activation, an increase in ROS induces lysosomal rupture and TMPyP rapidly relocates into the nucleus where it binds with high affinity to anionic DNA strands due to its cationic nature (Fig. 1D) [8,10].

$<$ Fig. $1>$

PDT has emerged as a clinically translatable stand-alone, adjuvant or neo-adjuvant treatment modality for various types of malignancies, including cancer but also as a novel antimicrobial therapeutic option through which development of resistance in microorganisms could be avoided [9,11]. Cationic porphyrins, such as TMPyP, have demonstrated to be great broad-spectrum antimicrobial PSs. Interestingly, combination treatment strategies have appeared as optimal options to improve clinical outcomes [12-14].

Porphyrins have many applications some of which include chemistry, medicine and biomimetic synthesis. This review illustrates the vast potential of the cationic porphyrin TMPyP within a full range of uses ranging from biomedical applications in cancer or microbial infections to biosensor development based on its interesting physicochemical properties. The purpose of this review is also to provide an insight into emerging applications of TMPyP as well as those which have shown significant potential in preclinical studies.

\section{TMPYP FOR CANCER THERAPY}

\section{The use of TMPyP in conventional studies}

The cationic porphyrin TMPyP has been studied for more than 25 years and has been described as a promising PS for PDT to treat localised neoplastic lesions. It has been confirmed by several groups that TMPyP selectively target cancer cells over non-tumorous cells in a wide variety of cancer models $[15,16]$. The following section summarises the most relevant publications including in vitro and in vivo studies using TMPyP. These studies corroborate the multiple possibilities that TMPyP can offer in light-based therapies for the treatment of cancer. 


\section{In vitro studies}

The in vitro pharmacokinetics of TMPyP has been widely evaluated. Findings showed clear differences in optimal PS tumour uptake and clearance levels depending on tumour type. While cells derived from solid tumours such as skin or cervix cancer, reached the highest TMPyP accumulation peak between 12-24 h incubation time, non-adherent cells such as leukemic HL-60 cells, presented a much faster accumulation kinetic reaching the maximum uptake at only $2 \mathrm{~h}$ $[7,17,18]$. In terms of clearance, Pizova et al. reported that after $24 \mathrm{~h}$ of incubation with TMPyP the subcellular concentration of PS decreased under 20\% [18]. However, other authors like Carvalho et al., and previously Grebenová et $a l$. , argue that although a significant percentage of the uptaken PS is released after that interval of time, the rest of it remains inside the cells bound to particular subcellular compartments of the endomembrane system for up to $3 \mathrm{~h}$ [19,20].

The subcellular localisation of TMPyP has also been reported by different groups as this parameter determines the mechanism of the photodynamic process. TMPyP mainly accumulates into lysosomes and the Golgi apparatus (oxygen rich organelles) but when used at high concentrations or after its photochemical activation, it rapidly binds to the nucleic acids in the nucleus [7,8,17,21,22]. The study performed by Patito and co-workers using murine colon carcinoma cells, proposed a possible mechanism of intracellular transport for this PS. They reported that prior to illumination, the molecule enters the cells via endocytosis, undergo the intracellular vesicle traffic pathway and end up accumulated inside lysosomes. Upon illumination, generated ROS induce lisosomal rupture, releasing the porphyrin into the cytoplasm [10]. They also proposed that oxidative stress is the main cause for the translocation of TMPyP into the nucleus via specific protein transporters. The same ROS-dependent mechanism had been previously described for different proteins by other authors [23]. The same group also performed HPLC analysis of cells treated with different PSs pre- and post-PDT treatment concluding that each PS uses a distinct transport mechanism depending on its chemical properties.

The use of TMPyP as a potential PS for cancer therapy relies on its ability to generate ROS upon light activation. This causes intracellular alterations of key cellular components such as the cytoskeleton or in some cases DNA oxidation, which altogether can induce different types of cell death. The mechanism by which TMPyP causes DNA photo-damage was thoroughly studied by Tada-Oikawa and collaborators using leukaemia cells [17]. They proposed that the ${ }^{1} \mathrm{O}_{2}$ generated after TMPyP photo-activation was the main responsible for the DNA damage detected. This photochemical reaction caused the formation of base 8-oxodG modifications, specifically in the guanines (8-oxo-7,8-dihydro-2'deoxyguanosine), rather than DNA breakage. They stated that this effect is TMPyP dose-dependent and more frequent in single stranded than double stranded DNA. The effects induced by TMPyP in the cytoskeleton have also been studied by different groups. Juarranz et al. described that TMPyP can alter cytoskeleton dynamics causing microtubule disorganisation and depolymerisation through its ability to bind tubulin. The results published by Cenklová et al. corroborated these data showing that HeLa and melanoma cells treated with TMPyP-PDT presented remarkable microtubule alterations (Fig. 2A and 2B) [7]. Upon illumination, TMPyP induced spindle aberrations and abnormalities in the mitotic index that only after sublethal PDT doses may be.

The therapeutic effect of TMPyP after photoactivation has been reported by several authors against a wide variety of human cancer cell lines including breast [18,21], melanoma [7,18], cervix [7,25], leukaemia [17], lung [21], ovary [21], colon $[10,26]$ and larynx models [19]. Normal cells have shown a reduced capacity to accumulate the porphyrin compared to cancerous cells [18], This may be a result of their slower metabolic rate leading to a reduced uptake of the photosensitiser and therefore to a decreased production of ROS upon photoactivation [27].

Multiple parameters influence PDT outcomes and the optimal $\mathrm{IC}_{50}$ concentration of TMPyP required to achieve a $50 \%$ of cell death. Some of these key parameteres are PS concentration, cell type, fluence, irradiance or light-drug interval. A study carried out by Pizova et al. using a range of TMPyP concentrations and light doses, against breast adenocarcinoma cells, melanoma cells and non-tumour fibroblasts, showed that the optimal therapeutic dose was $1 \mu \mathrm{M}$ follwed by $5 \mathrm{~J} . c m^{-}$ 
2 illumination at $414 \mathrm{~nm}$ [18]. They observed the highest resistance to treatment in non-tumour fibroblasts while breast cancer cells appeared to be the most sensible cell line. Conversely, a higher porphyrin dose was required to inactivate HeLa and G361 melanoma cells as reported by Cenklová et al. $(2,5 \mu \mathrm{M})$, using the same incubation time (24 h) with the PS (Fig. 2C). The increase in the concentration of TMPyP needed to achieve an antitumour effect against HeLa and G361 cells could be linked to the use of a lower light dose (1 J.cm-2 at $414 \mathrm{~nm})$. It is well-known that the anti-cancerous potential of PSs varies depending on fluence $\left(\mathrm{J} . \mathrm{cm}^{-2}\right)$ [19]. Thus, it is necessary to consider treatment-related parameters when comparing treatment outcomes, to further understand potential reasons for variability in therapeutic response.

The activation of TMPyP with UVA light (365 nm), also known as PUVA therapy, or by an ion-argon laser emitting light in the range of 458-515 nm have also been reported [17,19]. Based on its absorption spectrum, blue and red wavelenghts are the most commonly used for the activation of TMPyP (Fig. 1B). However, despite the higher efficiency of blue light to activate the porphyrin, it penetrates less into the tissues than red light. For that reason UVA light brings together a deeper penetration than blue light and a more efficient absorption by TMPyP than red light. This results in an increased ${ }^{1} \mathrm{O}_{2}$ generation upon photoactivation leading to an elevated cell death and a more effective PDT. However, the use of high intensity light sources could also promote local tissue heating which could trigger cell death by activating apoptotic or necrotic pathways induced by the thermal effect and not directly by PDT. In addition, long-term exposure to high-doses of this type of light has been associated with an increased risk of developing non-melanoma skin cancer. Further studies are still needed in order to assess the safety of using TMPyP for PUVA therapy [28].

Nowadays, only few studies have evaluated changes in gene expression after TMPyP-PDT treatments. Pizova et al. analysed the expression level of C-MYC and C-FOS, two transcription factors involved in cellular processes such as cell cycle modulation, proliferation, stress response and apoptosis [18]. They observed that while C-FOS was up-regulated after treatment in tumour cells, C-MYC was down-regulated in non-tumour cells, which indicates that especially tumour cells have a specific genomic response to TMPyP-triggered oxidative stress.

\section{In vivo studies}

The majority of the in vivo studies have aimed at deciphering the mechanism of action of TMPyP in neoplastic cells using different tumour models. However, the selection of the therapeutic dose of TMPyP required for PDT treatments has relied on simple 2D cell cultures systems of established cancer cell lines. Importantly, to ensure a possible clinical implementation of TMPyP, there are still crucial steps to fulfil in order to understand the implications that its administration would have in complex organisms for example, with a functional immune system.

In vivo studies describing TMPyP-PDT treatments are scarce. One of the first published studies was performed by Villanueva and collaborators [29]. In these studies, TMPyP was administered intravenously, at a concentration of 2.1 mg. $\mathrm{kg}^{-1}$, into Balb/c mice bearing a MS-2 fibrosarcoma. Tissue biodistribution analysis showed that TMPyP was preferentially accumulated in tumour tissue compared to healthy tissue, with the exception of the liver and spleen. The concentration of TMPyP found in the kidneys was minimal 24-48 h after the injection of the PS and fell beyond detection after one week, which suggests that the PS was excreted via the bile-gut pathway. Skin and muscle next to the tumour area only showed low concentrations of TMPyP one hour after injection. Importantly, no trace of PS was detected in the brain, which reinforces the idea that TMPyP does not cross the blood-brain barrier. The levels of TMPyP over time were also measured in the serum of rabbits injected with the same concentration of PS. Albumin and globulin were identified as the principal transporters of TMPyP.

In a later study, Villanueva et al. reported the effects of the TMPyP-PDT treatment in Balb/c mice-bearing fibrosarcoma [16]. For these tests, a double dose of TMPyP (4.1 mg.kg $\left.{ }^{-1}\right)$ was administrated intravenously. Twenty-four hours after the administration of the PS, tumours were illuminated with red light $(600-680 \mathrm{~nm})$ at a total light dose of 450 
${\mathrm{J} . \mathrm{cm}^{-2}}^{2}$. The highest degree of tumour necrosis was observed $24 \mathrm{~h}$ after the end of the treatment together with subcellular photodamage of the membranous systems and nuclei. Histological and ultrastructural analysis of the tumours showed that both cancer cells and capillary endothelium were affected (see Fig. 2D-F). The authors also reported that unlike their previous study, TMPyP was also found in the kidneys. This fact indicates that clearance through the kidneys plays also an important role when using high TMPyP concentrations.

A different strategy was carried out by Colombo et al. who applied repeated PDT treatments to mammary adenocarcinoma-bearing mice [30]. Irradiation was performed $1 \mathrm{~h}$ post-intratumoural injection of TMPyP using a fluence of $240 \mathrm{~J} . \mathrm{cm}^{-2}$ of blue-red light $(419-650 \mathrm{~nm})$. The treatment was repeated 4 times every 2 days for a total period of 6 days. Nine days after the first PDT treatment a significant reduction in the tumour diameter was reported. In this study, 15 out of the 17 mice that underwent PDT treatment showed long-term tumour regression, one partial regression and one was cured. However, and similarly to other published studies [31,32], once the PDT treatment was stopped, tumour relapse was observed, although at a slower rate than untreated mice, which negates the existence of any rebound effect.

Lastly, Gelfuso and collaborators tested in male rats the effect of applying an electric potential (iontophoresis) to enhance the TMPyP perfusion through the skin after topical administration [33]. The cationic properties of TMPyP in addition to the low-level electric current locally applied increased notably the ability of the PS to penetrate the stratum corneum of the skin. Interestingly, it was observed that TMPyP reached the epidermis after 10 minutes, achieving a higher accumulation of the PS in the area of interest than when using a classic passive delivery (Fig. 2G and $2 \mathrm{H}$ ).

$<$ Fig. 2>

\section{Combination therapies based on the use of TMPyP}

Despite its several advantages for cancer treatment, PDT is not considered yet as a potential first-line treatment modality except in a very limited number of cases, such as actinic keratosis and other dermatologic malignancies. Originally, the use of PDT was only considered suitable for the treatment of superficial small tumours mainly due to limited light penetration through tissues. However, recent technical advances in light delivery systems [34], have allowed to use PDT for the treatment of a wide range of solid tumours including brain, breast, esophageal, lung, prostate and pancreas $[2,35,36]$.

In the last decades, PDT has been explored as a promising strategy for the treatment of many types of cancer in combination with more conventional therapeutics modalities. Combination therapies are widely used in the clinic and have proven very successful outcomes [12]. The enhanced effectiveness obtained using combination therapies relays on the ability to target different cellular pathways limiting the ability of cancer cells to adapt to simultaneously induced toxic effects, minimising drug resistance [13]. However, the combination of multiple agents can also potentiate unwanted side effects. In this sense, PDT can offer key advantages for its application in combination cancer therapy. Firstly, PDT antitumour activity is preferentially triggered in the irradiated area, thereby minimising systemic toxicity and side effects. Secondly, due to its unique mechanism of action, PDT cytotoxic effect is only dependent on ROS generation and thus, PDT can be used in combination with other therapeutic modalities with very low risk of inducing cross-resistance [9,37].

Nowadays, lots of efforts have been made to improve PDT effectiveness for cancer treatment using multimodal strategies, including the combination of two PSs or the combination of PDT with other therapeutic modalities such as 
chemotherapy. Many of these investigations have involved the use of the cationic porphyrin TMPyP and are summarised in Table 1.

$<$ Table 1>

\section{Combination of TMPyP with other photosensitisers}

The combination of two or more drugs is commonly used in clinic as chemotherapeutic regimens. However, similar approaches have been poorly explored in the field of PDT. Few investigations had been published involving the combination of two PSs targeting different subcellular compartments, but the results are very promising [38-46]. Interestingly, most of these studies have involved the use of porphyrinic compounds. Among them, Villanueva et al. studied the combination of TMPyP and the PS zinc(II)-phthalocyanine $(\mathrm{ZnPc})$ incorporated into dipalmitoylphosphatidylcholine (DPPC) liposomes [8]. They found that the combined application of both PSs $\left(5 \times 10^{-8} \mathrm{M} \mathrm{ZnPc}+\right.$ $10^{-6} \mathrm{M}$ TMPyP) followed by $650 \pm 20 \mathrm{~nm}$ irradiation $\left(4 \mathrm{~mW} \mathrm{~cm}-2,2.4 \mathrm{~J} \mathrm{~cm}^{-2}\right)$ produced a synergistically enhanced lethal effect on HeLa (human cervix adenocarcinoma) and MCF-7 (human mammary adenocarcinoma) cells while monotherapies with single PSs did not significantly affect cell viability due to the low drug concentrations used and the short incubation time with the PSs. Remarkably, the incubation period needed when using this combination protocol was only 1 hour, highlighting the efficiency of their strategy. Authors confirmed that the observed synergistic lethal effect was due to the differential subcellular localisation of both PSs. TMPyP localised in lysosomes and ZnPc in the Golgi apparatus. It is well known the important role of subcellular localisation of PSs in the mechanism of tumour regression induced after PDT treatments. Due to the limited diffusion distance (approximately $30 \mathrm{~nm}$ ) and short lifetime in cells $\left(1 \times 10^{-7} \mathrm{~s}\right)$ of ${ }^{1} \mathrm{O}_{2}$ [47], phototoxicity primary occurs only in organelles surrounding PS accumulation area [3]. Thus, sublethal damage occurring simultaneously in two different cellular compartments would lead to a synergistically induced cell death.

Acedo et al. extended the previously mentioned investigation [6]. They described that combination PDT with $5 \times 10^{-8}$ $\mathrm{M} \mathrm{ZnPc}$ and $10^{-6} \mathrm{M}$ TMPyP induces apoptotic or necrotic cell death depending on the light dose used (91\% of apoptosis

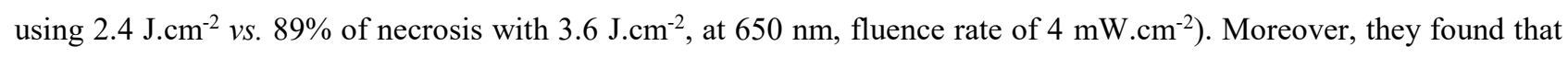
cells underwent apoptosis without losing their adhesion to substrate. Further studies are needed but these findings could be of key importance to reduce the risk of cancer recurrence and metastasis. In vivo experiments performed using a high metastatic amelanotic melanoma model showed an effective accumulation of both PSs in the tumour area $24 \mathrm{~h}$ after their intravenous administration (Fig. 3A) as well as a retardation of tumour growth after combined photodynamic treatment (Fig. 3B).

$<$ Fig. 3 $>$

Combination PDT strategies involving the use of porphyrins different than TMPyP have also been studied by other groups. Kessel and Reiners [48] have described that combination PDT with mono-l-aspartyl chlorin e6 (NPe6) and benzoporphyrin derivative (BPD) exhibited levels of photokilling greater than any of the monotherapies. After combined PDT treatment, murine hepatoma 1c1c7 cells and human non-small-cell lung cancer A549 cells showed large cytosolic vacuoles, typical for the caspase-independent cell death mode named paraptosis.

\section{Combination of TMPyP with chemotherapeutic agents}


Chemotherapy is the most common treatment option for cancer patients. However, high systemic toxicity and development of resistance to therapy clearly limit its effectiveness. Combinations of chemotherapy with other therapeutic modalities with non-overlapping toxicities, such as radiotherapy or surgery, are commonly used to improve therapeutic outcomes.

PDT monotherapy has shown promise for the treatment of early and locally advanced tumours $[49,50]$. However, due to its site-specific anticancer effect, PDT effectiveness is very limited for treating advanced metastatic cancers. In these cases, the use of systemic chemotherapy could prevent tumour recurrence and disease relapse improving patient outcomes.

Moreover, emerging evidences suggest that PDT plays an important role as adjuvant and neoadjuvant therapy to overcome cancer drug resistance. Remarkably, PDT could also be used to re-sensitise chemo- and radio-resistant cells through the photodamage of antiapoptotic factors and drug efflux pumps involved in classical multidrug resistance, among other mechanism $[9,51,52]$.

As recently reviewed by Luo et al., many studies have shown a synergistic enhancement of cancer therapy using concurrent PDT and chemotherapy [14]. Some of these combinations involved the use of TMPyP-PDT.

Kassab [53] analysed the effect of simultaneous administration of TMPyP and the chemotherapeutic agent adriamycin (ADM) using the human hepatocellular carcinoma cell line HepG2. Under dark conditions, TMPyP $\left(2 \mu \mathrm{g} . \mathrm{mL}^{-1}\right)$ plus ADM (5 $\left.\mu \mathrm{g} . \mathrm{mL}^{-1}\right)$ treatment enhanced cell death by 1.8 and 1.3 fold, compared to TMPyP or ADM monotherapy, respectively. After photoirradiation with green light $\left(200 \mathrm{~mW} \cdot \mathrm{cm}^{-2}\right.$ for $\left.20 \mathrm{~min}\right)$, the effectiveness of the combination treatment increased further by 2 fold $(26 \%$ cell viability after combination treatment vs. 67.6\% and 51.7\% after TMPyP or ADM treatment, respectively). Enzymatic assay for caspase-3 activity and transmission electron microscopy (TEM) images revealed that ADM monotherapy followed by illumination activated the apoptotic pathway while TMPyP-PDT monotherapy and combination treatment triggered necrotic cell death of HepG2 cells.

Guo et al. [54] developed a drug delivery system for targeted cancer therapy based on magnetic folic acid modified RNA nanoflowers for the simultaneous administration of TMPyP and the anticancer agent doxorubicin (DOX). In this study, they observed a synergistic therapeutic effect via the combination of these two compounds in the inactivation of

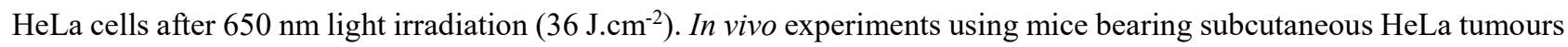
showed that treatment with magnetic RNA nanoflowers delivering TMPyP and DOX simultaneously (named by the authors $\mathrm{FA} / \mathrm{MNP} / \mathrm{RNA} \mathrm{NF} / \mathrm{D} / \mathrm{T}$ ) induced a greater regression in tumour volume in comparison with RNA nanoflowers containing DOX or TMPyP individually (FA/MNP/RNA NF/D or FA/MNP/RNA NF/T, respectively) (Fig. 4A). Furthermore, due to the fluorescent properties of DOX and TMPyP, these RNA nanoflower complexes allowed high contrast in vivo tumour imaging (Fig. 4B).

Shiao et al. [55] also worked on TMPyP-DOX combinations using nucleolin-specific aptamer-functionalised gold nanoparticles for the co-delivery of both compounds. In this system, exposure to $632 \mathrm{~nm}$ light triggered TMPyP activation and subsequent ROS generation. Reaction between ROS and DNA aptamers led to a rapid release of the therapeutic agent DOX in a spatio-temporally controlled manner. As in the previously mentioned study, these authors also found a synergistic effect in the inactivation of HeLa cells by the photochemotherapeutic combination (for all concentrations tested) after $20 \mathrm{~min}$ of $15 \mathrm{~mW} . \mathrm{cm}^{-2}$ irradiation $\left(18 \mathrm{~J} . \mathrm{cm}^{-2}\right)$. Therapeutic efficacy of multimodal nanoparticles (T/D:dsNPs) improved by 2.5 and 4.6 fold compared to TMPyP (T:ds-NPs) or DOX (D:ds-NPs) monotherapies, respectively (Fig. 4C). By monitoring the intracellular fluorescent signal of DOX molecules during the PDT process, they demonstrated that red light exposure triggered intracellular release of DOX and its relocalisation into cell nuclei, confirming the "gate keeper" property of TMPyP molecules in these nanoplatforms. Furthermore, this publication also 
demonstrated the synergistic effect of TMPyP and DOX combination (administered as free drugs or co-attached to gold nanoparticles) for the photokilling of multidrug resistant MCF-7R cells.

Another example of the application of PDT and nanoplatforms for spatio-temporally controlled release of chemotherapeutic agents was developed by Chen et al. [56]. They have developed TMPyP-incorporated G-quadruplex DNA-capped mesoporous silica nanoparticles loaded with DOX. After irradiation, G-quadruplex DNA moiety of the capping could be cleaved via the photosensitised production of ROS, thus opening the gates of the nanopores and releasing DOX. First, authors demonstrated the feasibility of the system in achieving a light-controlled release of cargo by substituting DOX for rhodamine B dye as a model molecule. Then, they treated HepG2 cells with the TMPyP-DOX loaded nanoconstructs, showing a remarkably higher cytotoxicity of the treatment in response to $440 \mathrm{~nm}$ light $\left(25 \mathrm{~mW}^{-\mathrm{cm}^{-}}\right.$ ${ }^{2}$ for $120 \mathrm{~s}$ ) (in comparison with combination treatment in dark conditions or TMPyP and DOX monotherapies) (Fig. 4D).

Yi et al. [57] have reported a photocontrollable drug release nanosystem for combining PDT, photothermal therapy (PTT) and chemotherapy. This system uses DOX and TMPyP intercalated into a DNA assembly immobilised on gold nanorods. Authors found that drugs were efficiently delivered to HeLa cells and released upon $1 \mathrm{~h}$ white light irradiation. In addition, they reported a synergistic effect between photo and chemotherapy but also between PDT and PTT (808 nm laser, $2.5 \mathrm{~W} . \mathrm{cm}^{-2}$ for $\left.6 \mathrm{~min}\right)$ of gold nanorods in combination with DOX chemotherapy $(6.5 \%$ cell viability after PDT + PTT + DOX vs. $40.6 \%$ or $47.7 \%$ cell viability after PTT + DOX or PDT + DOX therapies, respectively) (Fig. $4 \mathrm{E}$ ). Annexin V-FITC/PI double staining analysed by flow cytometry demonstrated that treatment using DOX-TMPyP-gold nanorods in combination with PTT and PDT enhanced therapeutic efficacy by inducing cell apoptosis.

$<$ Fig. $4>$

\section{ANTIMICROBIAL APPLICATIONS}

Resistance of bacteria to available antibiotics and the difficulty of developing new and more effective ones are global key issues in health care, proposing a threat to end the "golden era of antibiotics". Therefore, to find alternative strategies overcoming antibiotic resistance development is necessary.

Antimicrobial PDT (aPDT) is considered a promising alternative to antibiotic treatment for infections. aPDT is a noninvasive method to eliminate pathogens by the production of ROS, which cause an irreversible damage to the microorganism's main cell structures [58]. One of the most commonly studied PS in vitro aPDT is the cationic porphyrin TMPyP. The efficacy of TMPyP to eliminate bacteria and fungi has been studied in vitro in combination with antibiotics [59], PS loaded into nanoparticles for improved delivery [60] or bound to cyclodextrin compounds [61]. TMPyP has shown to effectively reduce the growth of both gram-positive and gram-negative bacteria as well as fungi such as $C$. albicans [62-64] (Table 2).

$<$ Table $2>$

Gram negative bacteria are known to be more resistant to many PSs used in aPDT compared to gram positive and fungi which shown to be successfully eliminated [65]. Remarkably, using a PS with cationic properties such as TMPyP had positive impact in eradicating gram-negative species such as $V$. anguillarum [66]. The effective killing of gram-negative 
bacteria with cationic PSs has been attributed to the strong positive charge of the PS which efficiently binds to the negatively charged cell wall of the pathogen, allowing it to enter the cells [67].

The cationic properties of TMPyP give it the advantage of selective binding to microbial cells due to their negative charge compared to mammalian cells. Also, the macromolecular structure of the PS and its cationic charge allows it to bind to microbes more rapid than by mammalian cells, where PS is taken up slowly by endocytosis. Rapid uptake and shorter illumination period (minutes) would minimise the damage of healthy cells by the treatment [68,69]. aPDT treatment have also been shown to be effective on antibiotic-resistant pathogens [70]. In addition, publication by Tavares et al., determined that partial inactivation of $E$. coli with porphyrin-based PS did not cause regrowth and resistance after 10 repeated cycles [71] making it a promising technique in clinical settings that could replace antibiotics in the treatment of infections.

\section{Gram positive bacteria}

\section{Staphylococcus aureus}

One of the most studied gram-positive bacteria is S. aureus. This bateria is known to cause skin, soft tissues and blood stream infections leading to life threatening conditions [72]. aPDT using different types of PSs, including porphyrins, has shown to reduce viability of methicillin-resistant $S$. aureus (MRSA) and methicillin-sensitive S. aureus (MSSA) strains in vitro $[73,74]$.

Maisch et al. used intense pulse light (IPL) (550 nm standard cut off filter) and short incubation time (10 s) to test the efficacy of TMPyP-aPDT against different types of pathogens, including MSSA and MRSA. When a concentration of 1 $\mu \mathrm{mol} . \mathrm{L}^{-1}$ TMPyP was used the toxicity induced was light-dose dependent, obtaining the highest killing efficacy after 4

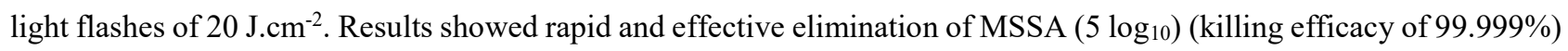
when 10 or $100 \mu \mathrm{mol} . \mathrm{L}^{-1}$ TMPyP concentrations were used with one light flash at $10 \mathrm{~J} . \mathrm{cm}^{-2}$ (Fig. 5Aa). Increasing the light dose to $40 \mathrm{~J} . \mathrm{cm}^{-2}$ or $80 \mathrm{~J} . \mathrm{cm}^{-2}$ did not result in any further inactivation of the cells (Fig. 5Ab) [74]. The authors further investigated whether the bacterial reduction observed was independent from antibiotic resistant pattern. Therefore, under identical experimental conditions, they tested the effect of TMPyP-PDT on MRSA. Similar bacterial growth reduction $\left(5 \log _{10}\right.$ ) was observed using MRSA strains when illuminated with one light flash of $10 \mathrm{~J} . \mathrm{cm}^{-2}$ [74]. A key advantage of using a short light-drug interval is that it minimizes the chance of developing pathogen resistance towards the treatment [75].

The destruction of the outer structure of bacterial cells with aPDT can facilitate the entry of antibiotics that target internal cell processes (e.g. chloramphenicol) or enhance the efficacy of antibiotics targeting the external structure of bacteria (e.g. ampicillin) [76].

\section{Enterococcus faecalis}

Diogo and co-workers compared the efficacy of $\mathrm{Zn}(\mathrm{II})$ chlorin e6 methyl ester ( $\mathrm{Zn}(\mathrm{II}) \mathrm{e}$ - Me) and TMPyP in the elimination of E. faecalis biofilm. After $15 \mathrm{~min}$ incubation with $0.1 \mathrm{mg} \cdot \mathrm{mL}^{-1} \mathrm{Zn}$ (II)e6Me or TMPyP, cells were illuminated for 60 or $90 \mathrm{~s}$ using a red LED device $\left(2.1{\mathrm{~J} . \mathrm{cm}^{-2}}\right.$ and $\left.3.15 \mathrm{~J}_{\mathrm{cm}} \mathrm{cm}^{-2}\right)$. Both PSs showed similar efficacy at reducing E. faecalis biofilm (Fig. 5B) [62].

Cieplik et al. used (2-((4pyridinyl) methyl)-1H-phenalen-1-one chloride) (SAPYR) and TMPyP (as positive control) to compare the PS efficacy in the elimination of E. faecalis monospecies and polyspecies biofilm. The illumination time and light intensity used in this study were $120 \mathrm{~s}$ and $600 \mathrm{~m} . \mathrm{W} . \mathrm{cm}^{-2}$, respectively. Results indicated that SAPYR was better at eliminating both monospecies and polyspecies biofilm $\left(5 \log _{10}\right)$. Data showed that even though TMPyP yield of 
absolute ${ }^{1} \mathrm{O}_{2}$ was 4 times higher than that of SAPYR, TMPyP did not result in CFU reduction in monospecies biofilm [77]. The difference in efficacy between the two PSs was suggested to be due to their molecular structure, as TMPyP has a larger molecular structure than SAPYR. This property together with its 4 positive charges per molecule, compared to 1 positive charge in SAPYR, makes it more difficult for TMPyP to penetrate the extracellular polymeric substance (EPS) structure of the biofilm [78]. Therefore, a strong electrostatic interaction with the negatively charged EPS takes place, delaying the penetration of the PS into the biofilm. This fact resulted in the generation of ${ }^{1} \mathrm{O}_{2}$ in the outer region of the biofilm structure, which promoted the killing of bacteria only located in the outer margins of the biofilm [77].

\section{Gram negative bacteria}

\section{Escherichia coli}

To improve the efficacy of aPDT, Hanakova et al. made a complex solution of photosensitiser: $\beta$-cyclodextrin (PS:CD) in different volume ratios (1:4, 1:1 and 2:1) with the following PS concentrations 12.5, 25, 50 and $100 \mu$ mol. $\mathrm{L}^{-1}$. Cells were illuminated using a LED light $\left(414 \mathrm{~nm}, 150 \mathrm{~J} . \mathrm{cm}^{-2}\right)$. After TMPyP-aPDT, a significant E. coli growth reduction was observed with the highest concentration $(100 \mu \mathrm{M}$ at ratio 2:1). In addition, TMPyP without CD resulted in reducing cell viability to $14 \%(100 \mu \mathrm{M}$ or $50 \mu \mathrm{M})$ or $84 \%(25 \mu \mathrm{M})$. On the other hand, Zinc-5, 10, 15, 20-tetrakis (4-sulphonatophenyl) porphyrin $\left(\mathrm{ZNTPPS}_{4}\right)$ was not efficient at eliminating E. coli, reducing cell viability by only $10 \%$ [61].

A recent study published by Huang et al. compared the efficacy of TMPyP and the anionic mesotetrakis (psulfonatofenyl) porphyrin $\left(\mathrm{TPPS}_{4}\right)$ to inactivate MRSA, E. coli and C. albicans. All pathogens were illuminated using a blue light $(405 \mathrm{~nm})$ at $10 \mathrm{~J} . \mathrm{cm}^{-2}, 50 \mathrm{~mW} . \mathrm{cm}^{2}$. TPPS 4 (100-200 nM) was more efficient at killing MRSA than TMPyP. However, at a concentration of $1 \mu \mathrm{M}$ both PSs showed a similar efficacy (Fig. 5Ca). TMPyP (1 $\mu \mathrm{M})$ was remarkably more successful at eradicating E. coli than $\mathrm{TPPS}_{4}(10 \mu \mathrm{M})$ (Fig. $\left.5 \mathrm{Cb}\right)$. However, when $100 \mathrm{mM}$ of potassium iodide (KI) was added to $\mathrm{TPPS}_{4}$ followed by illumination, $\mathrm{TPPS}_{4}$ was significantly more effective at eliminating gram negative bacteria. Dark toxicity $\left(1 \log _{10}\right)$ induced by TMPyP was only observed at a concentration of $10 \mu \mathrm{M}$. As for C. albicans, both PSs reduced the viability of the pathogen (TMPyP - $10 \mu \mathrm{M}$, TPPS4 - $1 \mu \mathrm{M}$ ) (Fig. 5Cc) [79].

$<$ Fig. 5 $>$

\section{Fungi}

\section{Candida albicans}

Diogo et al. have performed a comparative study evaluating the efficacy of TMPyP and Zn(II)e6Me for the destruction of an in vitro model of endodontic biofilm caused by C. albicans. Prior to illumination, biofilm cells were incubated with $0.1 \mathrm{mg} . \mathrm{mL}^{-1}$ TMPyP or $\mathrm{Zn}(\mathrm{II}) \mathrm{e} 6 \mathrm{Me}$ for a period of $15 \mathrm{~min}$, to allow the entry of PS into the cells. Cells were then illuminated for 60 or $90 \mathrm{~s}$ using a red LED device $\left(2.1 \mathrm{~J} . \mathrm{cm}^{-2}\right.$ and $\left.3.15 \mathrm{~J} . \mathrm{cm}^{-2}\right)$. Results of biofilm biomass quantification using safranin red assay showed that TMPyP is effective in removing $>60 \%$ of biofilm after $90 \mathrm{~s}$ illumination, which is similar to the inhibition achieved using Zn(II)e6Me. However, when using shorter illumination time (60 s) a significant difference in the efficacy of biofilm eradication between the two PSs was observed, being Zn(II)e6Me more efficient than TMPyP (Fig. 6A). Authors concluded that even though TMPyP and Zn(II)e6Me showed a similar effect in removing biofilm, Zn(II)e6Me has an advantage over TMPyP due to its availability from natural resources as well as its really low 
toxicity in the absence of light. In dark conditions, the biofilm biomass reduction of cells incubated with $\mathrm{Zn}(\mathrm{II}) \mathrm{e} 6 \mathrm{Me}$ was $8.6 \%$ compared to the $15.5 \%$ reduction in cells incubated with TMPyP [62].

Another comparative study has been published by Pereira Gonzales and co-workers. Authors compared the efficacy of TMPyP and exeporfinium chloride (XF-73) for the elimination of planktonic and biofilm cells of C. albicans. Prior to illumination, planktonic and biofilm cells were incubated for $15 \mathrm{~min}$ (planktonic cells) or $4 \mathrm{~h}$ (biofilm cells) with increasing PS concentrations 0-2 $\mu \mathrm{M}$. Lately, planktonic cells were illuminated for $15 \mathrm{~min}\left(12.1 \mathrm{~J} . \mathrm{cm}^{-2}\right)$ and biofilm cells for $60 \mathrm{~min}$ (48.2 J.cm-2) using incoherent blue light (fluence rate: $13.4 \mathrm{~mW} . \mathrm{cm}^{-2}$ ). Results of planktonic cells showed that 15 min incubation with $0.5 \mu \mathrm{M}$ of XF-73 followed by illumination was successful at reducing the bacterial growth (6 $\left.\log _{10}\right)$ where a higher concentration of TMPyP $(2 \mu \mathrm{M})$ was needed to reach the same values [63].

As for biofilm cells, longer incubation time, higher PS concentrations and higher fluence rate were required. Results showed that using $1 \mu \mathrm{M}$ of XF-73 was enough to reduce bacterial growth $\left(5 \log _{10}\right)$, where $50 \mu \mathrm{M}$ of TMPyP was used to achieve the same results. The difference in their efficacy was due to the strong electrostatic interaction of TMPyP (positively charged) with the biofilm matrix (EPS) (negatively charged) decreasing the penetration of the PS into the biofilm.

Eichner et al. tested TMPyP in C. albicans, MRSA and Enterohemorrhagic E. coli (EHEC). Cells were incubated for $10 \mathrm{~s}$ with $1 \mu \mathrm{mol} \mathrm{l}{ }^{-1}$ followed by 10 or $60 \mathrm{~s}$ illumination $\left(50 \mathrm{~mW} . \mathrm{cm}^{-2}\right)$ with visible light $\left(0.5\right.$ and $\left.3 \mathrm{~J} . \mathrm{cm}^{-2}\right)$. TMPyP at a concentration of $1 \mu \mathrm{mol} . \mathrm{l}^{-1}$ followed by a $0.5 \mathrm{~J} . \mathrm{cm}^{-2}$ illumination dose was efficient at reducing MRSA and EHEC bacterial growth by $99.9 \%$. Increasing the TMPyP concentration up to $100 \mu \mathrm{mol}^{-1} \mathrm{l}^{-1}$ they achieved a $5 \log _{10}$ bacterial growth reduction after illumination. As for C. albicans, a $5 \log _{10}$ reduction was observed using a higher light dose (12

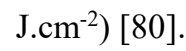

\section{Paracoccidioides brasiliensis}

Almeida et al. have studied P. brasiliensis susceptibility to TMPyP-aPDT. P. brasiliensis cell suspensions were incubated with 10, 25 and $50 \mu \mathrm{M}$ TMPyP for $60 \mathrm{~min}$ and then illuminated using white light for $15 \mathrm{~min}\left(108 \mathrm{~J} . \mathrm{cm}^{-2}\right), 30$ $\min \left(216 \mathrm{~J} . \mathrm{cm}^{-2}\right)$ or $60 \mathrm{~min}\left(432 \mathrm{~J} . \mathrm{cm}^{-2}\right)$ (density power: $\left.120 \mathrm{~mW} . \mathrm{cm}^{-2}\right)$. CFU values were recorded after 5 days of growth. Authors determined that induction of cell death was PS and light dose dependent. Significant cell death was observed in cells treated with TMPyP $>25 \mu \mathrm{M}$ and illuminated for $30 \mathrm{~min}$. Authors investigated the mortality rate using $50 \mu \mathrm{M}$ TMPyP. Only 15 min illumination were necessary to kill $\sim 95 \%$ of cells ( $3 \log _{10}$ ) (Fig. $6 \mathrm{~B}$ group B). Moreover, cells did not exhibit dark toxicity. In addition, cells exposed to light in the absence of TMPyP showed no reduction in cell viability

(Fig. 6B group A) [81].

$<$ Fig. 6>

\section{EMERGING APPLICATIONS OF TMPYP}

In the last few years an increased interest in the porphyrin TMPyP has given rise to a wide variety of novel applications of this PS. Based on its strong affinity for nucleic acids and its high quantum yield of ROS production, TMPyP has demonstrated to be an effective compound to be used for cancer theranostics, molecule biosensing, nanoparticle-switch for controlled drug release or as a cargo for targeted PS delivery in PDT. In this section, we present some of the most innovative applications of this porphyrin and its relevance in different fields. 


\section{Nanotechnology and TMPyP}

Nanomedicine is defined as the application of nano-sized devices for the improved outcome of medicine [82]. This field is undergoing a rapid development due to the improved benefits that can boost conventional therapies for the treatment of different diseases, including cancer. Some main benefits are: increased water solubility of drugs, possibility of targeted therapy, improved therapeutic index and reduced systemic toxicity and side effects [83,84]. In particular, porphyrins such as TMPyP incorporated into nanodevices, have been studied for different purposes that vary from lighttriggered drug release for controlled drug delivery, nanoparticle-driven PS delivery or biosensing.

\section{Nanoparticle-mediated delivery of photosensitisers}

Nanoparticles represent an effective vehicle for the delivery of porphyrins. One of their biggest advantages is that they can be used for the co-delivery of two or more therapeutic agents. In this way, nanoparticles can be loaded with both the sensitiser and a chemotherapeutic drug, for combination cancer therapy using PDT plus chemotherapy. This approach has led to better outcomes than using a combination of both monotherapies administered in two steps.

Guo and collaborators have exploited this idea and synthesised magnetic RNA nanoflowers modified with folic acid, for the co-delivery of TMPyP and the chemotherapeutic agent doxorubicin, as detailed in the combination therapy section [54]. The coating layer of folic acid improved the selectivity of the device against tumour cells both in vitro and in vivo (Fig. 7A). In a different study, Wang et al. linked TMPyP to carbon nanodots (CDots) taking advantage of the electrostatic force arisen between them [85]. Carbon dots conjugates proved to increase the ${ }^{1} \mathrm{O}_{2}$ quantum yield and biocompatibility of TMPyP, resulting in a more efficient treatment and an enhancement of the anticancer effect of TMPyP-PDT against HeLa cells (Fig. 7B).

Li et al. have reported the synthesis of silica nanoparticles with TMPyP attached [86]. Their results indicated that while in an alkaline $\mathrm{pH}$ environment the silica particles quench the TMPyP ${ }^{1} \mathrm{O}_{2}$ production, in weak acidic solutions (characteristic of tumours environments) TMPyP is released and ROS production is recovered. This approach improved the tumour selectivity of PDT treatments.

Lastly, Nonell and collaborators exploited the surface charge of silica nanoparticles (SiNP) to bind via electrostatic adsorption the porphyrin TMPyP [87]. They reported that the concentration of TMPyP-SiNP needed to induce cytotoxicity on HeLa cells was ten times lower compared to free TMPyP (Fig. 7C). Similarly to other authors, they observed that the encapsulated PS localised mainly in lysosomes.

$<$ Fig. 7 $>$

\section{Light-triggered controlled drug release}

Upon photoactivation, the porphyrin TMPyP produces ROS at a very efficient rate. This effect has been widely used for PDT treatments but recently, some groups have taken advantage of it and implemented TMPyP in the design of nanosystems. As a result, nanoparticles made of different materials have been loaded with chemotherapeutic agents and functionalised with TMPyP. ROS generated upon illumination degrade the matrix of the nanoparticles and trigger the release of the cargo in a spatial and temporal controlled manner.

A study conducted by Chen and co-workers utilised silica nanoparticles capped with G-quadruplexes of DNA to encapsulate doxorubicin [56]. As detailed in the above combination therapy section, due to their strong affinity, TMPyP bound to the G-quadruplexes and was used to both act as a PS and to open the gates of the nanopores of the particles, triggering the release of doxorubicin. Shiao et al. substituted silica nanoparticles for gold nanoparticles functionalised 
with aptamers [55]. As aptamers are also based on nucleic acids, TMPyP was attached to them and used to induce the release of doxorubicin bound to the complexes. It was observed an improved subcellular uptake of the drugs by HeLa cells overexpressing the nucleolin receptor in their surface due to the aptamers-targeting efficiency.

\section{Biosensors and molecule detection}

The use of TMPyP for the detection and quantification of nucleic acid based molecules, such as G-quadruplexes, have been reported taking advantage of the high affinity of this porphyrin towards DNA and its fluorescent properties. In a recent publication, Monteiro et al. used a graphene oxide nanoplatform to non-covalently bind TMPyP [88]. The fluorescence of the porphyrin was quenched in the hybrid platforms but, upon the addition of oligonucleotide sequences corresponding to G-quadruplexes, TMPyP was tritiated and detached from the graphene oxide, allowing the recovery of its characteristic red fluorescence. Therefore, these nanoplatforms could be used to quantify the presence of DNA-based structures.

\section{Stabilisation of G-quadruplexes}

G-quadruplexes are secondary structures of the DNA formed as a result of the interaction of nucleotides in guanine rich sequences [88]. They have been described as potent molecular targets for cancer therapy since their stabilisation can lead to cell growth and cell division inhibition [89]. The planar structure and size of TMPyP, together with its high affinity for DNA, makes it an excellent candidate for G-quadruplex stabilisation and telomerase inhibition.

The promoter of the vascular endothelial growth factor (VEGF), an important gene promoting tumour angiogenesis, has been described to contain a guanine-rich strand, which can form G-quadruplexes. A study conducted by Taka et al. compared the efficacy of two perylene derivatives as well as TMPyP, to form G-quadruplexes and to selectively bind to the VEGF promoter silencing the gene in lung cancer cells [90]. They reported a reduction in the mRNA expression and also a decrease in protein levels. Thus, these findings prove the feasibility of using TMPyP as a potential novel antiangiogenic agent for cancer therapy.

Alternatively, Zhao and collaborators developed ZnCdSe-based quantum dots with TMPyP electrostatically attached as a novel "turn-off-on" system for the detection of G-quadruplexes [91]. First, the "turn-off" state of the system relies on the quenching effect that the porphyrin causes on the quantum dot, resulting in a lack of its characteristic fluorescence. The "turn-on" process was then triggered by the detection of G-quadruplexes by the system which, due to the high affinity of TMP and DNA molecules, and the repelling negative charges of both the quantum dots and the nucleic acids, caused the release of the porphyrin from the quantum dots allowing them to recover their fluorescence (Fig. 8).

$<$ Fig. $8>$

\section{CONCLUSION}

Overall, porphyrins represent a fascinating group of molecules with attractive properties and multiple applications. The investigations summarised in this review support the idea that the cationic porphyrin TMPyP has an invaluable potential for its application in biomedical research.

Combination therapy seems a useful strategy to enhance the efficacy of TMPyP-PDT for cancer treatment. Moreover, it has been demonstrated that application of TMPyP-PDT in multimodal nanoplatforms is a promising tool for achieving 
a light-controlled release of chemotherapeutic agents, minimising both drug resistance of cancer cells and cytotoxicity in healthy tissues.

On the other hand, the use of TMPyP in aPDT for the elimination of pathogens has also shown promising results. Combination aPDT strategies could lead to the development of more selective treatments. Unlike antibiotics, repeated aPDT treatments have not shown to induce resistance in bacteria. The above-mentioned findings corroborate that combining aPDT and antibiotics could enhance the overall treatment outcome minimising antibiotic resistance. All this makes TMPyP-aPDT a potential therapeutic option for treating resistant strains in a non-invasive way, which could facilitate its clinical translation.

\section{Acknowledgements}

We would like to thank the invaluable contributions of authors of the cited publications. We would like to express our deep gratitude to Prof Ángeles Villanueva and Prof Stephen Pereira. The financial support from the Ramón Areces Foundation is gratefully acknowledged. AT thanks the Autonomous University of Madrid for her FPI-UAM fellowship.

\section{REFERENCES}

1. $\quad$ Senge MO and Davis M. J. Porphyr. Phthalocyanines 2010; 14: 557-567.

2. Baskaran R, Lee J and Yang S-G. Biomater. Res. 2018; 22.

3. Benov L. Med. Princ. Pract. 2015; 24: 14-28.

4. $\quad$ Nagaya T, Nakamura YA, Choyke PL and Kobayashi H. Front. Oncol. 2017; 7.

5. Zhang J, Jiang C, Figueiró Longo JP, Azevedo RB, Zhang H and Muehlmann LA. Acta Pharm. Sin. B 2018; 8: 137-146.

6. Acedo P, Stockert JC, Cañete M and Villanueva A. Cell Death Dis. 2014; 5: 1-12.

7. Cenklová V. J. Photochem. Photobiol. B Biol. 2017; 173: 522-537.

8. Villanueva A, Stockert JC, Cañete M and Acedo P. Photochem. Photobiol. Sci. 2010; 9: $295-297$.

9. $\quad$ Spring BQ, Rizvi I, Xu N and Hasan T. Photochem. Photobiol. Sci. 2015; 14: 1476-1491.

10. Patito IA, Rothmann C and Malik Z. Biol. Cell 2001; 93: 285-291.

11. Hamblin MR and Abrahamse H. Molecules 2018; 23: 3190.

12. Mokhtari RB, Homayouni TS, Baluch N, Morgatskaya E, Kumar S, Das B and Yeger H. Oncotarget 2017; 8: 38022-38043.

13. Zimmermann GR, Lehar J and Keith CT. Drug Discov. Today 2007; 12: 34-42.

14. Luo D, Carter KA, Miranda D and Lovell JF. Adv. Sci. 2017; 4.

15. Vrouenraets MB, Visser GWM, Loup C, Meunier B, Stigter M, Oppelaar H, Stewart FA, Snow GB and van Dongen G. Int. J. CANCER 2000; 88: 108-114.

16. VIllanUeVA A, CAGGIARI L, JORI G and MILANESI C. J. Photochem. Photobiol. B-BIOLOGY 1994; 23: 49-56.

17. Tada-Oikawa S, Oikawa S, Hirayama J, Hirakawa K and Kawanishi S. Photochem. Photobiol. 2009; 85: 13911399.

18. Pizova K, Bajgar R, Fillerova R, Kriegova E, Cenklova V, Langova K, Konecny P and Kolarova H. $J$. Photochem. Photobiol. B Biol. 2015; 142: 186-196. 
19. Carvalho VCM, Melo CAS, Bagnato VS and Perussi JR. Laser Phys. 2002; 12: 1314-1319.

20. Grebenova D, Cajthamlova H, Holada K, Marinov J, Jirsa M and Hrkal Z. J. Photochem. Photobiol. BBIOLOGY 1997; 39: 269-278.

21. Sengupta D, Mazumdar ZH, Mukherjee A, Sharma D, Halder AK, Basu S and Jha T. J. Photochem. Photobiol. B Biol. 2018; 178: 228-236.

22. Berg K and Moan J. Photochem. Photobiol. 1997; 65: 403-409.

23. CURRY PM and LEVY JG. Photochem. Photobiol. 1993; 58: 374-379.

24. Juarranz A, Espada J, Stockert JC, Villanueva A, Polo S, Dominguez V and Canete M. Photochem. Photobiol. 2001; 73: 283-289.

25. Juarranz A, Villanueva A, Díaz V and Cañete M. J. Photochem. Photobiol. B Biol. 1995; 27 : 47-53.

26. Siboni G, Amit-Patito I, Weizman E, Waintraub-Porat M, Weitman H, Ehrenberg B and Malik Z. Cancer Lett. 2003; 196: 57-64.

27. Tita SPS and Perussi JR. Brazilian J. Med. Biol. Res. 2001; 34: 1331-1336.

28. Ling TC, Clayton TH, Crawley J, Exton LS, Goulden V, Ibbotson S, McKenna K, Mohd Mustapa MF, Rhodes LE, Sarkany R and Dawe RS. Br. J. Dermatol. 2016; 174: 24-55.

29. VILLANUEVA A and JORI G. CANCER Lett. 1993; 73: 59-64.

30. Colombo LL, Vanzulli SI, Villanueva A, Canete M, Juarranz A and Stockert JC. Int. J. Oncol. 2005; 27: 10531059.

31. Oku N, Saito N, Namba Y, Tsukada H, Dolphin D and Okada S. Biol. Pharm. Bull. 1997; 20: 670-673.

32. Engbrecht BW, Menon C, Kachur A V, Hahn SM and Fraker DL. CANCER Res. 1999; 59: 4334-4342.

33. Gelfuso GM, Gratieri T, Souza JG, Thomazine JA and Lopez RF V. Eur. J. Pharm. Biopharm. 2011; 77: 249256.

34. Mang TS. PHOTODIAGNOSIS Photodyn. Ther. 2004; 1: 43-48.

35. Anand S, Ortel BJ, Pereira SP, Hasan T and Maytin E V. CANCER Lett. 2012; 326: 8-16.

36. Dougherty TJ. J. Clin. Laser Med. Surg. 2002; 20: 3-7.

37. Casas A, Di Venosa G, Hasan T and Batlle A. Curr. Med. Chem. 2011; 18: 2486-2515.

38. Koren H, Schenk GM, Jindra RH, Alth G, Ebermann R, Kubin A, Koderhold G and Kreitner M. J. Photochem. Photobiol. B-BIOLOGY 1996; 36: 113-119.

39. Briza T, Kralova J, Cigler P, Kejik Z, Pouckova P, Vasek P, Moserova I, Martasek P and Kral V. Bioorg. Med. Chem. Lett. 2012; 22: 82-84.

40. Cincotta L, Szeto D, Lampros E, Hasan T and Cincotta AH. Photochem. Photobiol. 1996; 63: $229-237$.

41. Peng Q, Warloe T, Moan J, Godal A, Apricena F, Giercksky KE and Nesland JM. CANCER Res. 2001; 61: 5824-5832.

42. NELSON JS, LIAW LHL, LAHLUM RA, COOPER PL and BERNS MW. J. Natl. CANCER Inst. 1990; 82: 868-873.

43. Wang Y, Lin Y, Zhang H and Zhu J. J. Cancer Res. Clin. Oncol. 2016; 142: 813-821.

44. Schneider-Yin X, Kurmanaviciene A, Roth M, Roos M, Fedier A, Minder EI and Walt H. PHOTODIAGNOSIS Photodyn. Ther. 2009; 6: 12-18.

45. Gyenge EB, Luescher D, Forny P, Antoniol M, Geisberger G, Walt H, Patzke G and Maake C. Photochem. Photobiol. 2013; 89: 150-162.

46. Kessel D and Reiners Jr. JJ. Photochem. Photobiol. 2014; 90: 889-895.

47. Plaetzer K, Krammer B, Berlanda J, Berr F and Kiesslich T. LASERS Med. Sci. 2009; 24: 259-268. 
48. Kessel D and Reiners Jr. JJ. Photochem. Photobiol. 2017; 93: 1502-1508.

49. Azzouzi AR, Vincendeau S, Barret E, Cicco A, Kleinclauss F, van der Poel HG, Stief CG, Rassweiler J, Salomon G, Solsona E, Alcaraz A, Tammela TT, Rosario DJ, Gomez-Veiga F, Ahlgren G, Benzaghou F, Gaillac B, Amzal B, Debruyne FMJ, Fromont G, Gratzke C and Emberton M. Lancet Oncol. 2017; 18: 181191.

50. Huggett MT, Jermyn M, Gillams A, Illing R, Mosse S, Novelli M, Kent E, Bown SG, Hasan T, Pogue BW and Pereira SP. Br. J. Cancer 2014; 110: 1698-1704.

51. Celli JP, Solban N, Liang A, Pereira SP and Hasan T. LASERS Surg. Med. 2011; 43: 565-574.

52. Pogue BW, O’Hara JA, Demidenko E, Wilmot CM, Goodwin IA, Chen B, Swartz HM and Hasan T. CANCER Res. 2003; 63: 1025-1033.

53. Kassab K. Acta Biochim. Biophys. Sin. (Shanghai). 2009; 41: 892-899.

54. Guo Y, Li S, Wang Y and Zhang S. Anal. Chem. 2017; 89: 2267-2274.

55. Shiao YS, Chiu HH, Wu PH and Huang YF. ACS Appl. Mater. Interfaces 2014; 6: 21832-21841.

56. Chen C, Zhou L, Geng J, Ren J and Qu X. SMALL 2013; 9: 2793-2800.

57. Yi Y, Wang H, Wang X, Liu Q, Ye M and Tan W. ACS Appl. Mater. Interfaces 2017; 9: 5847-5854.

58. Lopes D, Melo T, Santos N, Rosa L, Alves E, Clara Gomes M, Cunha A, Neves MGPMS, Faustino MAF, Domingues MRM and Almeida A. J. Photochem. Photobiol. B-BIOLOGY 2014; 141: 145-153.

59. Di Poto A, Sbarra MS, Provenza G, Visai L and Speziale P. Biomaterials 2009; 30: 3158-3166.

60. Gonzalez-Delgado JA, Castro PM, Machado A, Araujo F, Rodrigues F, Korsak B, Ferreira M, Tome JPC and Sarmento B. Int. J. Pharm. 2016; 510: 221-231.

61. Hanakova A, Bogdanova K, Tomankova K, Pizova K, Malohlava J, Binder S, Bajgar R, Langova K, Kolar M, Mosinger J and Kolarova H. Microbiol. Res. 2014; 169: 163-170.

62. Diogo P, Fernandes C, Caramelo F, Mota M, Miranda IM, Faustino MAF, Neves MGPMS, Uliana MP, de Oliveira KT, Santos JM and Goncalves T. Front. Microbiol. 2017; 8.

63. Gonzales FP, Felgentraeger A, Baeumler W and Maisch T. Future Microbiol. 2013; 8: 785-797.

64. Quiroga ED, Gabriela Alvarez M and Durantini EN. FEMS Immunol. Med. Microbiol. 2010; 60: $123-131$.

65. MALIK Z, LADAN H and NITZAN Y. J. Photochem. Photobiol. B-BIOLOGY 1992; 14: 262-266.

66. Merchat M, Bertolini G, Giacomini P, Villanueva A and Jori G. J. Photochem. Photobiol. B-BIOLOGY 1996; 32: $153-157$.

67. Alves E, Costa L, Carvalho CMB, Tome JPC, Faustino MA, Neves MGPMS, Tome AC, Cavaleiro JAS, Cunha A and Almeida A. BMC Microbiol. 2009; 9.

68. Dai T, Huang Y-Y and Hamblin MR. PHOTODIAGNOSIS Photodyn. Ther. 2009; 6: 170-188.

69. Demidova TN and Hamblin MR. Int. J. Immunopathol. Pharmacol. 2004; 17: 245-254.

70. Adolfo Vera DM, Haynes MH, Ball AR, Dai T, Astrakas C, Kelso MJ, Hamblin MR and Tegos GP. Photochem. Photobiol. 2012; 88: 499-511.

71. Tavares A, Carvalho CMB, Faustino MA, Neves MGPMS, Tome JPC, Tome AC, Cavaleiro JAS, Cunha A, Gomes NCM, Alves E and Almeida A. Mar. Drugs 2010; 8: 91-105.

72. Tong SYC, Davis JS, Eichenberger E, Holland TL and Fowler Jr. VG. Clin. Microbiol. Rev. 2015; 28: 603-661.

73. Fu X, Fang Y and Yao M. Biomed Res. Int. 2013.

74. Maisch T, Spannberger F, Regensburger J, Felgentraeger A and Baeumler W. J. Ind. Microbiol. Biotechnol. 2012; 39: 1013-1021.

75. Liu Y, Qin R, Zaat SAJ, Breukink E and Heger M. J. Clin. Transl. Res. 2015; 1: 140-167. 
76. Branco TM, Valerio NC, Rodrigues Jesus VI, Dias CJ, Neves MGPMS, Faustino MAF and Almeida A. PHOTODIAGNOSIS Photodyn. Ther. 2018; 21: 285-293.

77. Cieplik F, Spaeth A, Regensburger J, Gollmer A, Tabenski L, Hiller K-A, Baeumler W, Maisch T and Schmalz G. Free Radic. Biol. Med. 2013; 65: 477-487.

78. Stewart PS. Biotechnol. Bioeng. 1998; 59: 261-272.

79. Huang L, El-Hussein A, Xuan W and Hamblin MR. J. Photochem. Photobiol. B-BIOLOGY 2018; 178: $277-$ 286.

80. Eichner A, Gonzales FP, Felgentraeger A, Regensburger J, Holzmann T, Schneider-Brachert W, Baeumler W and Maisch T. Photochem. Photobiol. Sci. 2013; 12: 135-147.

81. Almeida LM, Zanoelo FF, Castro KP, Borissevitch IE, Soares CMA and Goncalves PJ. Photochem. Photobiol. 2012; 88: 992-1000.

82. Moghimi SM, Hunter AC and Murray JC. FASEB J. 2005; 19: 311-330.

83. Whitesides GM. Nat. Biotechnol. 2003; 21: 1161-1165.

84. Colombeau L, Acherar S, Baros F, Arnoux P, Gazzali AM, Zaghdoudi K, Toussaint M, Vanderesse R and Frochot C. In Sortino, S, ed. LIGHT-RESPONSIVE NANOSTRUCTURED SYSTEMS FOR APPLICATIONS IN NANOMEDICINE. Vol 370. Topics in Current Chemistry-Series. GEWERBESTRASSE 11, CHAM, CH6330, SWITZERLAND: SPRINGER INTERNATIONAL PUBLISHING AG, 2016; 113-134.

85. Wang J, Zhang Z, Zha S, Zhu Y, Wu P, Ehrenberg B and Chen JY. Biomaterials 2014; 35: $9372-9381$.

86. Li W, Lu W, Fan Z, Zhu X, Reed A, Newton B, Zhang Y, Courtney S, Tiyyagura PT, Ratcliff RR, Li S, Butler E, Yu H, Ray PC and Gao R. J. Mater. Chem. 2012; 22: 12701-12708.

87. Gallardo A, Morales J, Comas-Barceló J, Gallavardin T, Acedo P, Villanueva A and Nonell S. Silica-Based Nanostructured Materials for Biomedical Applications. Woodhead Publishing Limited; 2015.

88. Monteiro AR, Ramos CI V., Fateixa S, Moura NMM, Neves MGPMS and Trindade T. ACS Omega 2018; 3: 11184-11191.

89. Neidle S. J. Med. Chem. 2016; 59: 5987-6011.

90. Taka T, Joonlasak K, Huang L, Lee TR, Chang S-WT and Tuntiwechapikul W. Bioorg. Med. Chem. Lett. 2012; 22: $518-522$.

91. Zhao D, Fan Y, Gao F, Yang TM, Pan J, Zhang S, Taka T, Joonlasak K, Huang L, Randall Lee T, Chang SWT and Tuntiwechapikul W. J. Biol. Inorg. Chem. 2015; 22: 518-522. 
Table 1. Summary of studies using TMPyP-PDT combined with other therapeutic modalities.

\begin{tabular}{|c|c|c|c|c|}
\hline \multicolumn{5}{|c|}{ Combination of TMPyP with other PS } \\
\hline PS & NPs & In vitro & In vivo & Ref. \\
\hline $\mathrm{ZnPc}$ & $\mathrm{ZnPc}$ incorporated in liposomes & $\checkmark$ & $\mathrm{X}$ & Villanueva et al. [8] \\
\hline $\mathrm{ZnPc}$ & $\mathrm{ZnPc}$ incorporated in liposomes & $\checkmark$ & $\checkmark$ & Acedo el et al. [6] \\
\hline \multicolumn{5}{|c|}{ Combination of TMPyP with chemotherapeutic agents } \\
\hline Chemo & NPs & In vitro & In vivo & Ref. \\
\hline ADM & $\mathrm{X}$ & $\checkmark$ & $\mathrm{X}$ & Kassab [53] \\
\hline DOX & Magnetic RNA nanoflowers & $\checkmark$ & $\checkmark$ & Guo et al. [54] \\
\hline DOX & Aptamer-functionalised AuNPs & $\checkmark$ & $\mathrm{X}$ & Shiao et al. [55] \\
\hline DOX & G-quadruplex DNA-capped mesoporous silica NPs & $\checkmark$ & $\mathrm{X}$ & Chen et al. [56] \\
\hline
\end{tabular}

ZnPc: zinc(II)-phthalocyanine; ADM: adriamycin; DOX: doxorubicin. 
Table 2. Summary of different studies evaluating the efficacy of TMPyP against different pathogens.

\begin{tabular}{|c|c|c|c|c|c|}
\hline Pathogen & PS concentration & Light type & Light doses $\left(\mathrm{J} . c m^{-2}\right)$ & $\begin{array}{l}\text { Reduction of } \\
\text { microbial growth } \\
\left.\text { (CFU } \log _{10}\right)\end{array}$ & Reference \\
\hline MRSA & $10 \mu \mathrm{M}$ & IPL & 10 & 5.0 & $\begin{array}{c}\text { Maisch et al. } \\
\text { [74] }\end{array}$ \\
\hline MSSA & $10 \mu \mathrm{M}$ & IPL & 10 & 5.0 & $\begin{array}{c}\text { Maisch et al. } \\
{[74]}\end{array}$ \\
\hline $\begin{array}{l}\text { Enterococcus } \\
\text { faecalis }\end{array}$ & $100 \mu \mathrm{M}$ & Blue light & 72 & $<1$ & $\begin{array}{c}\text { Cieplik et al. } \\
\text { [77] }\end{array}$ \\
\hline $\begin{array}{l}\text { C. albicans } \\
\text { planktonic cells }\end{array}$ & $2 \mu \mathrm{M}$ & Blue light & 12.1 & 6.0 & $\begin{array}{c}\text { Pereira Gonzales } \\
\text { et al. }[63]\end{array}$ \\
\hline $\begin{array}{l}\text { C. albicans } \\
\text { biofilm cells }\end{array}$ & $50 \mu \mathrm{M}$ & Blue light & 48.2 & 5.0 & $\begin{array}{c}\text { Pereira Gonzales } \\
\text { et al. }[63]\end{array}$ \\
\hline $\begin{array}{l}\text { Paracoccidioides } \\
\text { brasiliensis }\end{array}$ & $50 \mu \mathrm{M}$ & White light & 108 & 3.0 & $\begin{array}{l}\text { Almeida et al. } \\
\text { [81] }\end{array}$ \\
\hline
\end{tabular}

MSSA: methicillin-susceptible Staphylococcus aureus; MSRA: methicillin-resistant Staphylococcus aureus; IPL: intense pulse light (wavelength $550 \mathrm{~nm}$ ). 
A

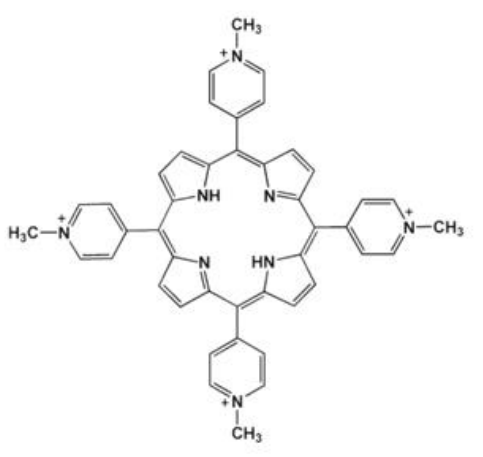

C

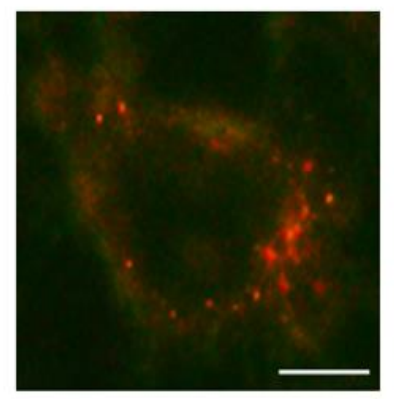

B

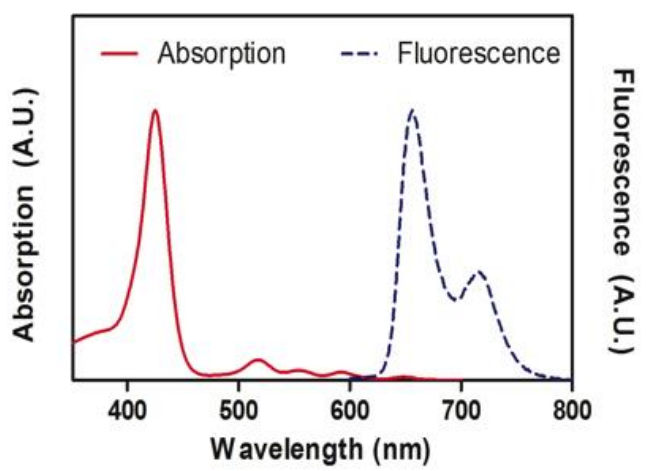

D

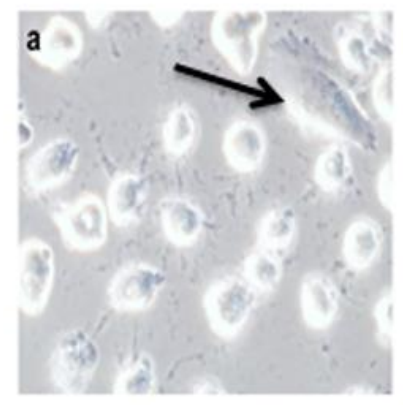

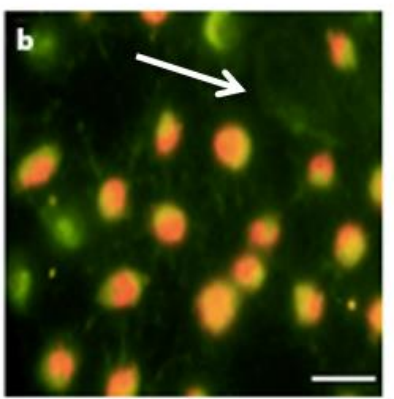

Fig. 1. (A) Chemical structure of TMPyP. (B) Absorption (red line) and emission (blue line) spectra of TMPyP in aqueous solution. (C) Red emission fluorescence of TMPyP indicating its subcellular localisation (lysosomes) in HeLa cells under blue excitation (426 nm). Scale bar: $5 \mu \mathrm{m}$. Reproduced with permission from [8]. (D) Relocalisation of TMPyP in HeLa cells after a TMPyP-PDT treatment. (a) Phase contrast image. (b) Dead cells showing relocalisation of TMPyP to the nucleus after PDT treatment. Detection of TMPyP is based on its red fluorescence emission under blue light excitation. Live cells (indicated with an arrow) did not show a nuclear TMPyP fluorescence pattern. Scale bar: $10 \mu \mathrm{m}$. 

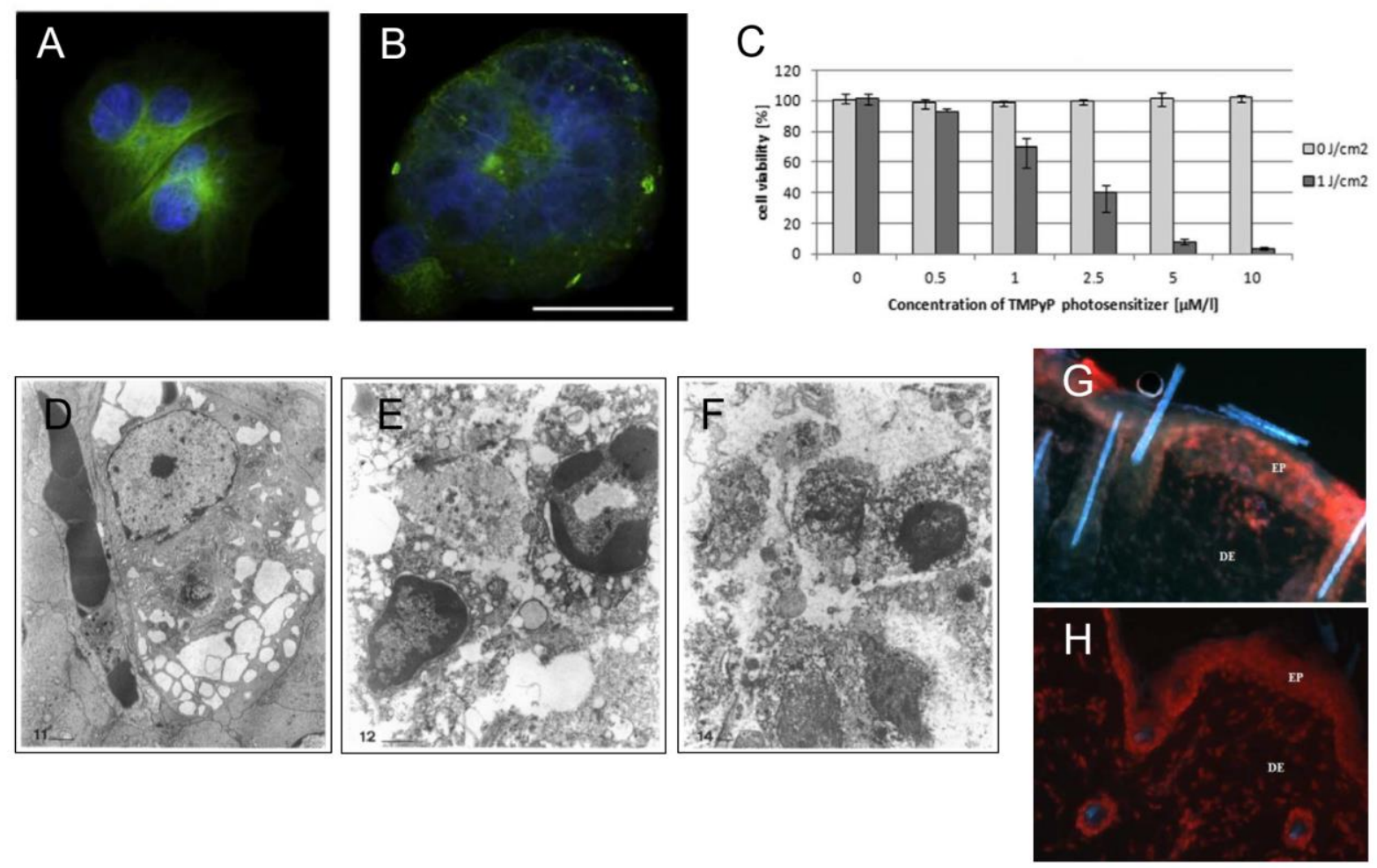

Fig. 2. (A, B) Microtubules organisation (green) of untreated control G361 cells (A) and treated cells (B) incubated with $2.5 \mu \mathrm{M}$ TMPyP $2 \mathrm{~h}$ post PDT-treatment (fluence $1 \mathrm{~J} . \mathrm{cm}^{-2}$ ). Nuclei counterstained with DAPI (blue). Scale bar $=10 \mu \mathrm{m}$. Reproduced with permission from [7]. (C) Cell viability of G361 cells after different TMPyP-PDT treatments. Reproduced with permission from [7]. (D-F) Electron micrographs of tumours derived from Balb/c mice bearing a MS2 fibrosarcoma $3 \mathrm{~h}$ (D), $12 \mathrm{~h}$ (E) and $24 \mathrm{~h}$ (F) after PDT treatment (4.1 mg.kg-1 TMPyP, light dose: $450 \mathrm{~J} . \mathrm{cm}^{-2}$ ). Scale bar $=1 \mu \mathrm{m}$. Reproduced with permission from [16]. $(\mathrm{G}, \mathrm{H})$ Fluorescence images of Wistar rat skin 10 min after passive $(\mathrm{G})$ or anodal iontophoresis $(\mathrm{H})$ using a hydroxyethylcellulose gel containing $5.0 \mathrm{mg} . \mathrm{g}^{-1}$ TMPyP. EP: Epidermis; DE: Dermis. Reproduced with permission from [33]. 
A

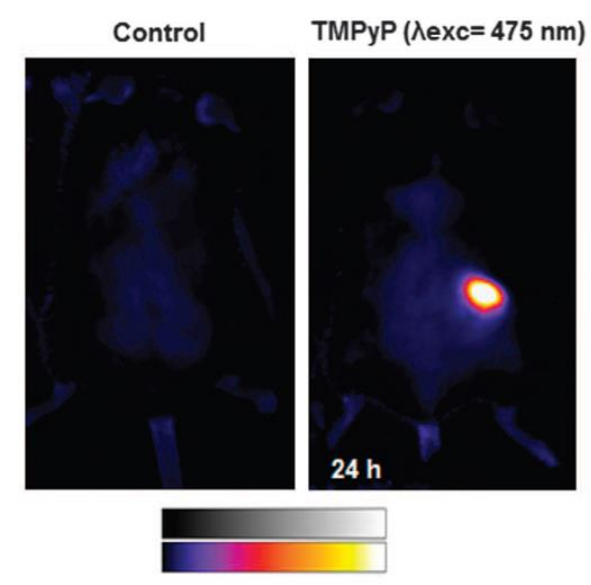

B

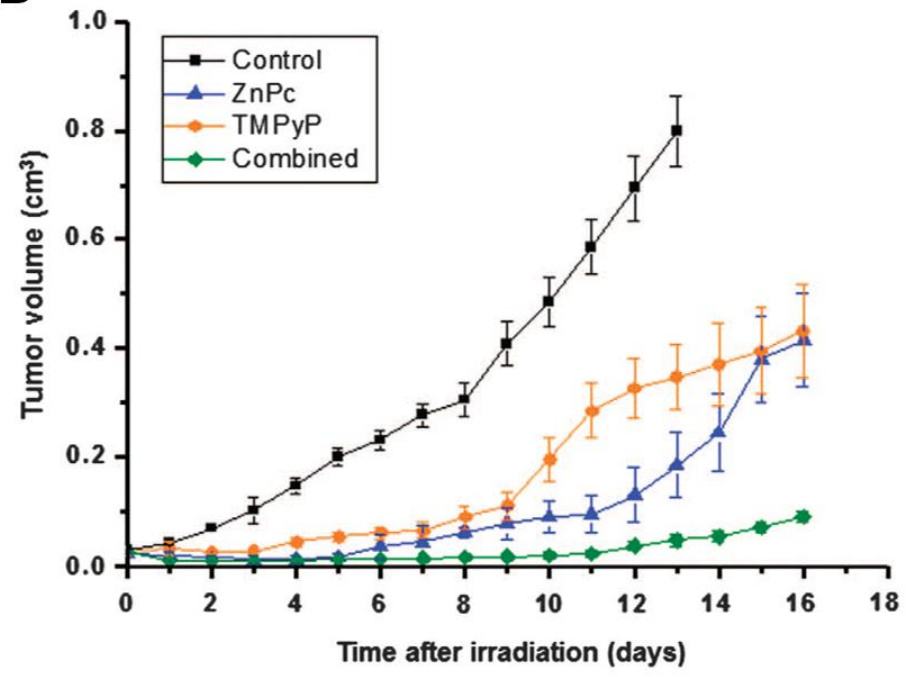

Fig. 3. (A) Detection of TMPyP fluorescence in the tumour area $24 \mathrm{~h}$ after intravenous administration. Edited and reproduced with permission from [6]. (B) Mean tumour volume after different PDT treatments (300 J.cm ${ }^{-2}$ ) performed 24 $\mathrm{h}$ after administration of $0.5 \mathrm{mg} \cdot \mathrm{kg}^{-1} \mathrm{ZnPc}$ and/or $4.1 \mathrm{mg} . \mathrm{kg}^{-1} \mathrm{TMPyP}$. Reproduced with permission from [6]. 
A

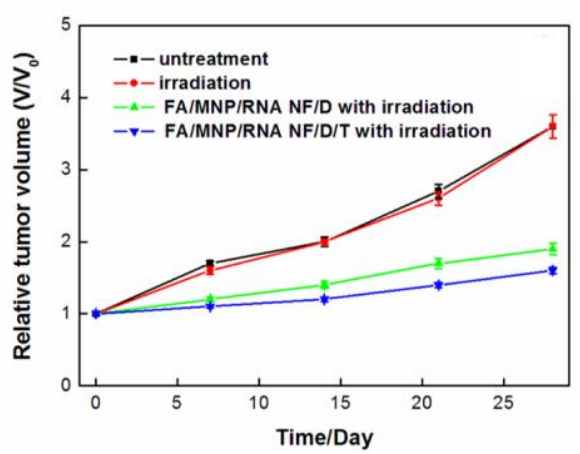

C

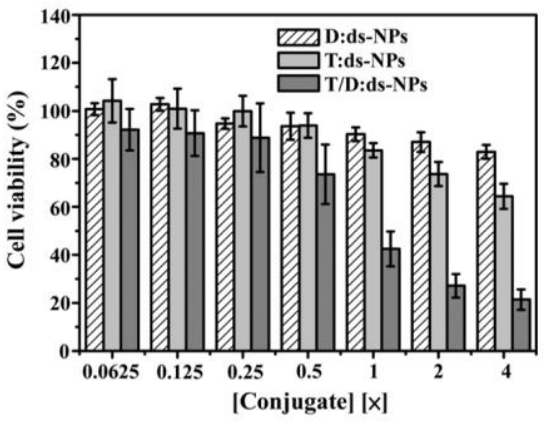

$\mathrm{B}$

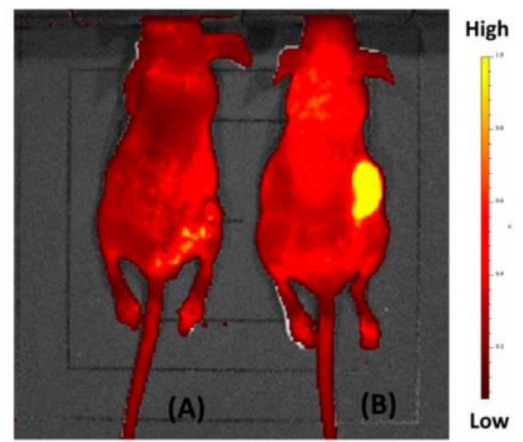

E
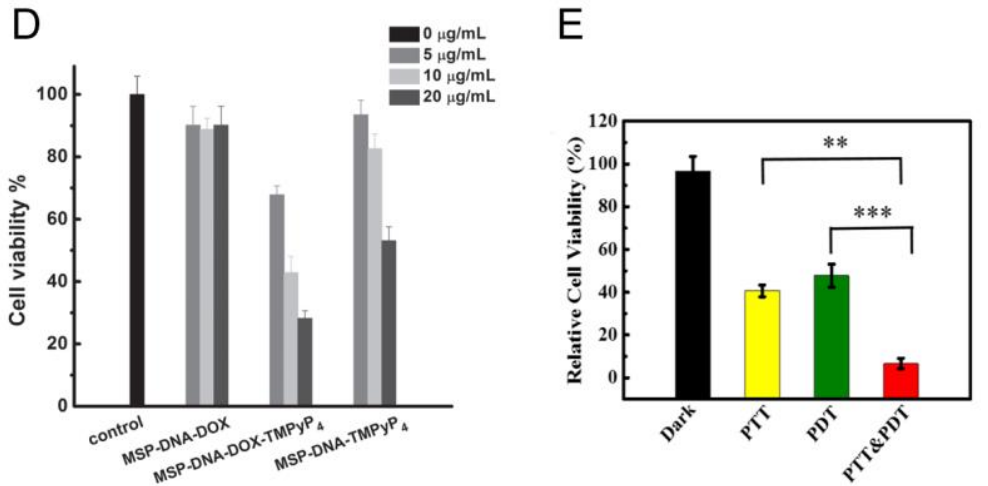

Fig. 4. (A) Change of relative tumour volume upon different treatments. Reproduced with permission from [54]. (B) Fluorescence images of (A) control and (B) HeLa tumour-bearing mice $24 \mathrm{~h}$ post-injection of FA/MNP/RNA NF/D. Reproduced with permission from [54]. (C) Viability of HeLa cells upon different treatments followed by red light exposure. Reproduced with permission from [55]. (D) Survival of HepG2 cells treating for $3 \mathrm{~h}$ with DOX, TMPyP or DOX-TMPyP loaded nanoparticles followed by illumination. Reproduced with permission from [56]. (E) Cytotoxicity induced by DOX-TMPyP/ds-NRs against HeLa cells after PTT, PDT or combined PTT + PDT treatments. Reproduced with permission from [57]. 
A

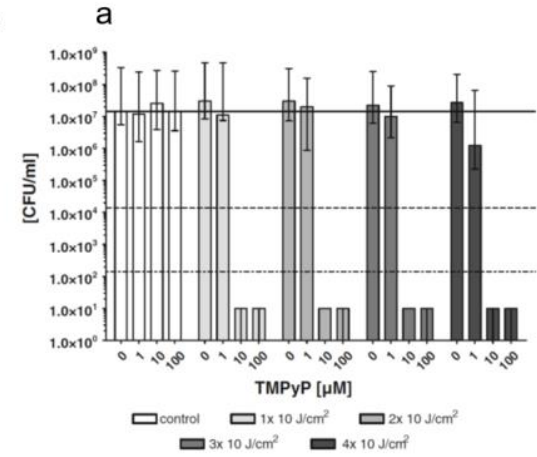

C

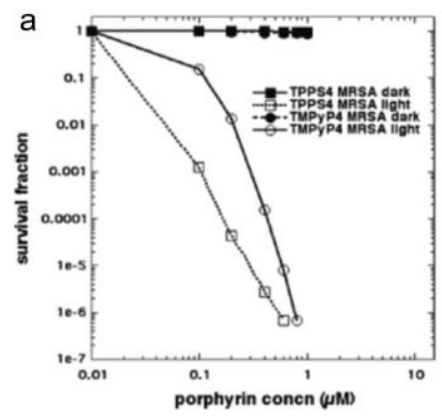

b

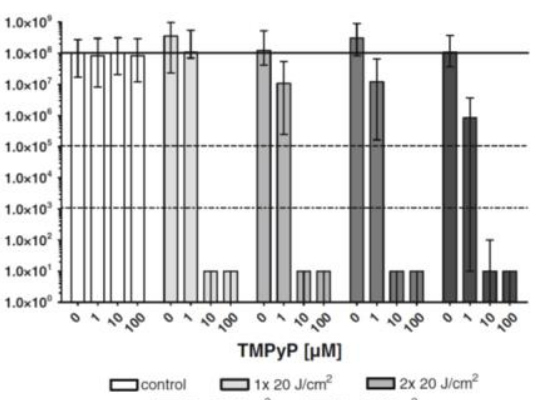

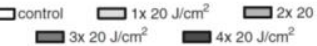

b

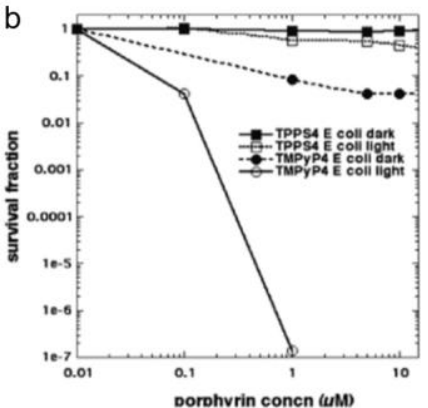

B

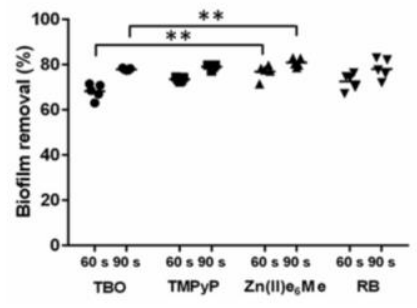

C

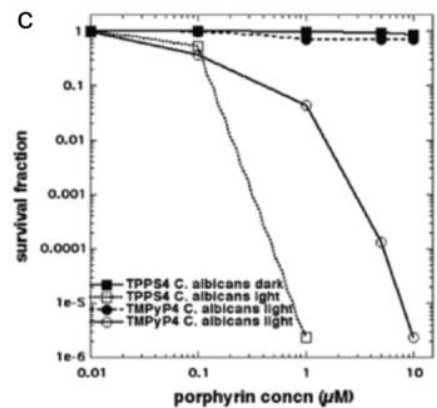

Fig. 5. (Aa) CFU value of MSSA cells treated with different TMPyP concentrations and illuminated with multiple light flashes $(1-4 \mathrm{x})$ at $83 \mathrm{~ms}\left(10 \mathrm{~J}_{\mathrm{cm}} \mathrm{cm}^{-2}\right.$. (Ab) CFU value of MSSA cells treated with same TMPyP concentrations but

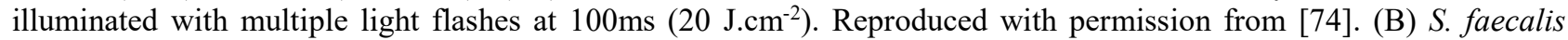
biofilm biomass removal after aPDT treatment. Quantification was done using safranin red assay. TBO: Toluidine Blue O; RB: Rose Bengal. Reproduced with permission from [62]. (C) MRSA (a), E. coli (b) and C. albicans (c) treated with

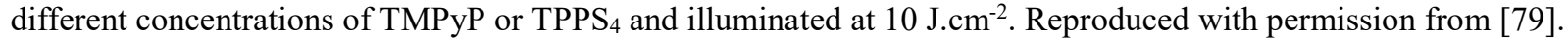


A

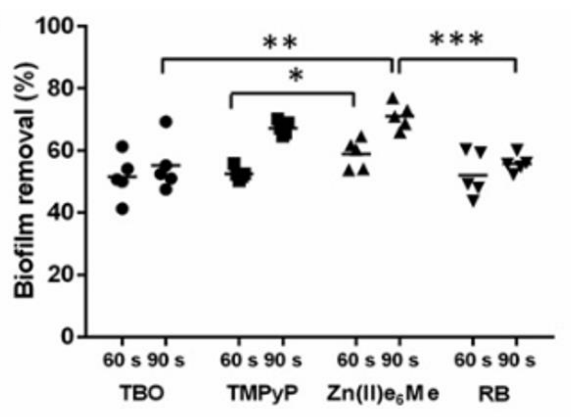

B

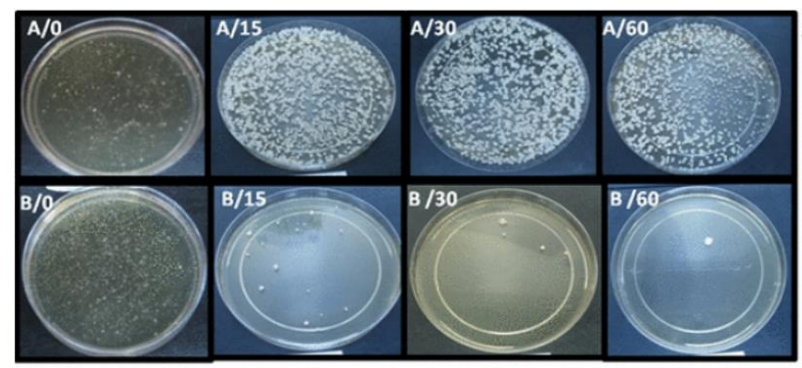

Fig. 6. (A) C. albicans biofilm biomass removal after aPDT treatment. Quantification was done using safranin red assay. Reproduced with permission from [62]. (B) P. brasiliensis cells treated with light only (group A) or with 50 $\mu \mathrm{M}$ TMPyP

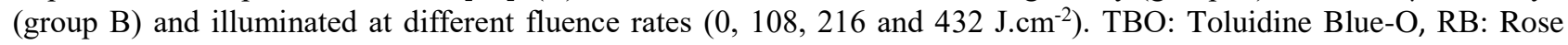
Bengal. Reproduced with permission from [81]. 
A

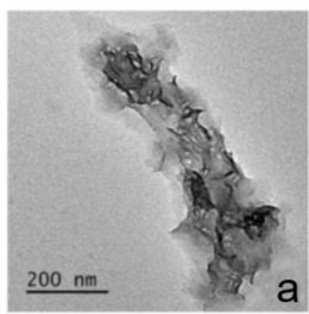

C a

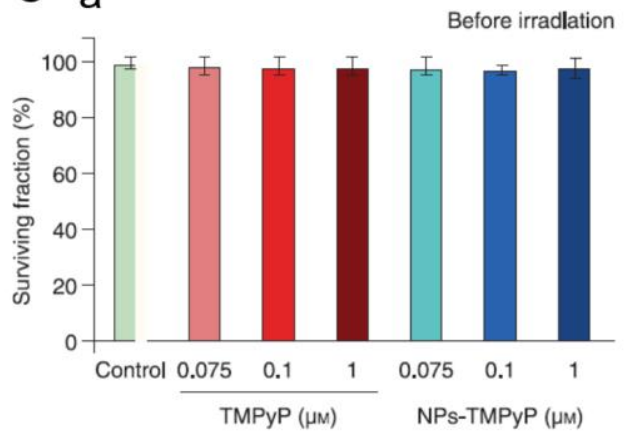

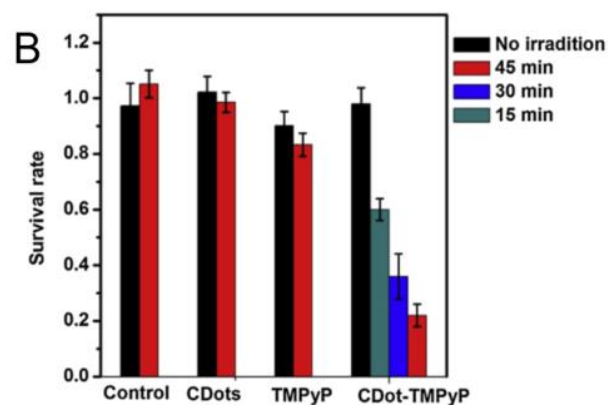

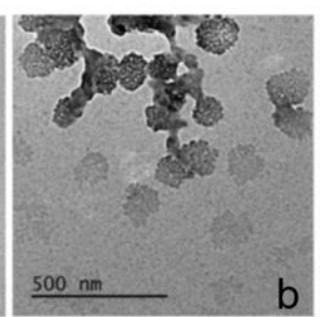

b

$\underline{0.5 \mathrm{\mu m}}$

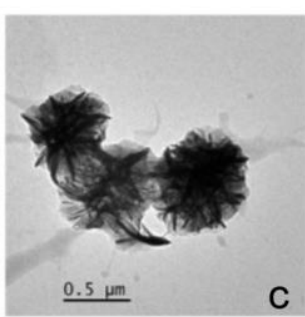

After irradiation

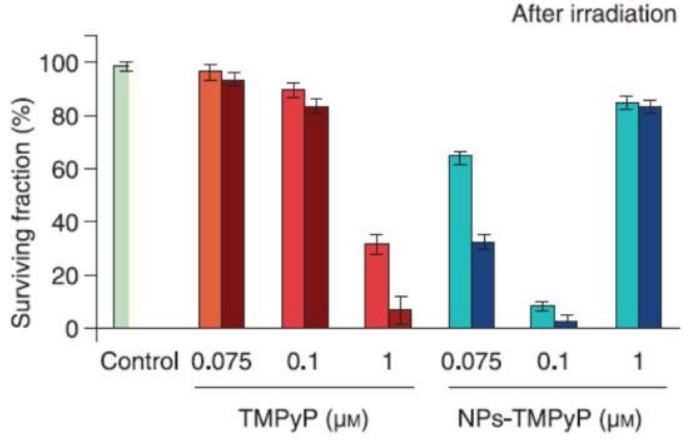

Fig. 7. (A) TEM images of rolling circle transcription products using 2 (a), 6 (b) or 10 (c) h reaction times. Reproduced with permission from [54]. (B) MTT assay performed in Hela cells after incubation with TMPyP (7 mg.mL $\left.\mathrm{mL}^{-1}\right), \mathrm{CDots}(10$ mg.mL $\left.\mathrm{mL}^{-1}\right)$ or CD-TMPyP $\left(7 \mathrm{mg} \cdot \mathrm{mL}^{-1}-10 \mathrm{mg} \cdot \mathrm{mL}^{-1}\right)$ for $2 \mathrm{~h}$, followed by different irradiation doses. Reproduced with permission from [85]. (C) In vitro photodynamic activity of free or TMPyP encapsulated into mesoporous silica nanoparticles tested in HeLa cells by trypan blue assay, before (a) or after (b) irradiation. Columns correspond to 4.8 $\mathrm{J} . \mathrm{cm}^{-2}$ irradiation (light colour) or $7.2 \mathrm{~J} . \mathrm{cm}^{-2}$ irradiation (dark colour). Reproduced with permission from [87]. 


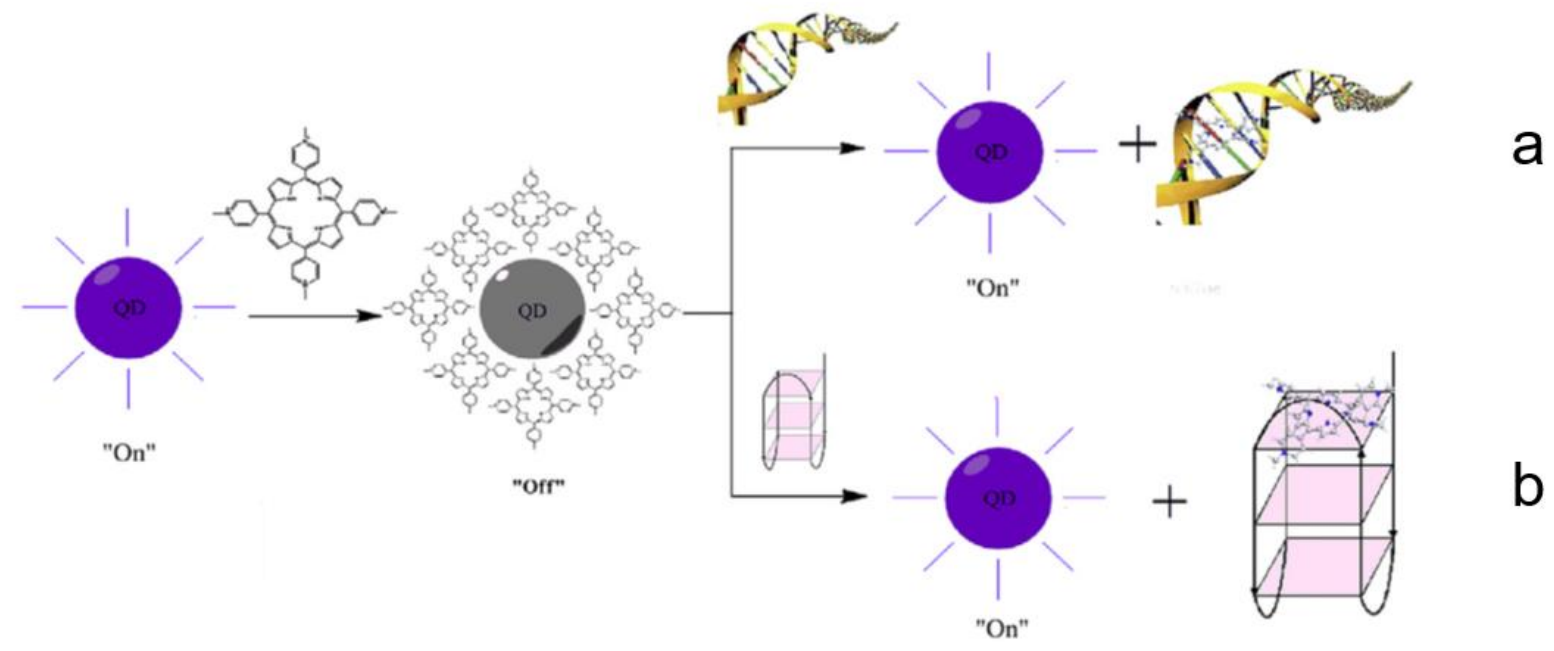

Fig. 8. Mechanism of the reversible "turn-off-on" mode developed by Zhao et al.. The loss of the characteristic fluorescence of the QDs is represented by a grey QD ("turn-off" process). The recovery of the fluorescence upon interaction with genetic material is represented by a purple QD ("turn-off-on" process). The mechanism of "QD-TMPyPctDNA" is shown in (a) and the one for "QD-TMPyP-G-quadruplex" is shown in (b). Reproduced with permission from [91]. 
Multimodal use of the porphyrin TMPyP: from cancer therapy to antimicrobial applications

Andres Garcia-Sampedro, Andrea Tabero, Ismahan Mahamed, Pilar Acedo

This review summarises the current state-of-the-art applications of the cationic porphyrin meso-tetra(4-N-methylpyridyl)porphine (TMPyP) for the treatment of cancer as well as its implementation in antimicrobial PDT. It also highlights the potential emerging applications of this porphyrin.

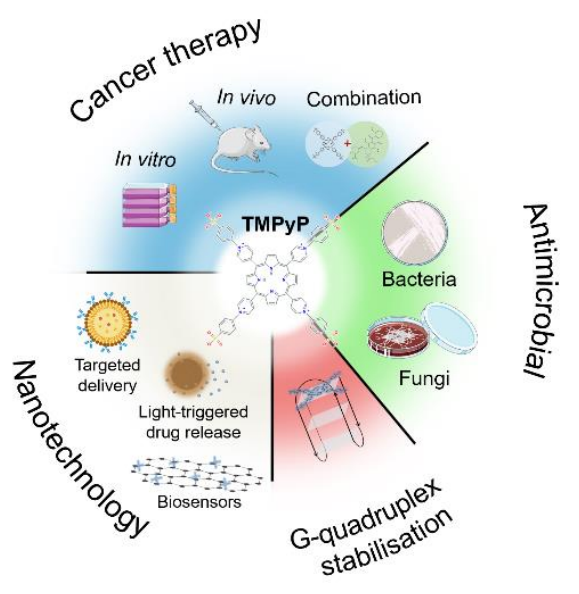

